\title{
Chapter 8 \\ Evaluation and Tuning of Model Trajectories and Spreading Rates in the Baltic Sea Using Surface Drifter Observations
}

\author{
Joakim Kjellsson, Kristofer Döös, and Tarmo Soomere
}

\begin{abstract}
Results from experiments with surface drifters in the Baltic Sea in 2010 2011 are presented and discussed. In a first experiment, 12 SVP-B (Surface Velocity Program, with Barometer) drifters with a drogue at 12-18 m depth were deployed in the Baltic Sea. In a second experiment, shallow drifters extending to a depth of $1.5 \mathrm{~m}$ were deployed in the Gulf of Finland. Results from the SVP-B drifter experiment are compared to results from a regional ocean model and a trajectory code. Differences between the observed SVP-B drifters and simulated drifters are found for absolute dispersion (i.e., squared displacement from initial position) and relative dispersion (i.e., squared distance between two initially paired drifters). The former is somewhat underestimated since the simulated currents are neither as fast nor as variable as those observed. The latter is underestimated both due to the abovementioned reasons and due to the resolution of the ocean model.

For the shallower drifters, spreading in the upper 1-2 $\mathrm{m}$ of the Gulf of Finland is investigated. The spreading rate is about $200 \mathrm{~m} /$ day for separations $<0.5 \mathrm{~km}$, $500 \mathrm{~m} /$ day for separations below $1 \mathrm{~km}$ and in the range of $0.5-3 \mathrm{~km} /$ day for separations in the range of $1-4 \mathrm{~km}$. The spreading rate does not follow Richardson's law. The initial spreading, up to a distance of about $d=100-150 \mathrm{~m}$, is governed by the power law $d \sim t^{0.27}$ whereas for larger separations the distance increases as $d \sim t^{2.5}$.
\end{abstract}

\footnotetext{
J. Kjellsson $(\varangle) \cdot$ K. Döös

Department of Meteorology, Bolin Centre for Climate Research, Stockholm University, Svante Arrhenius väg 16C, 10691 Stockholm, Sweden

e-mail: joakim@misu.su.se

K. Döös

e-mail: doos@misu.su.se

\section{T. Soomere}

Wave Engineering Laboratory, Institute of Cybernetics at Tallinn University of Technology, Akadeemia tee 21, 12618 Tallinn, Estonia

e-mail: soomere@cs.ioc.ee
}

T. Soomere

Estonian Academy of Sciences, Kohtu 6, 10130 Tallinn, Estonia 


\subsection{Background}

Many studies of the ocean rely on Lagrangian trajectories. Knowledge of the origin and destination of a water particle, as well as the spreading of several initially closely located particles, is necessary for a number of purposes, for example estimating the fate of oil spills (Soomere et al. 2010) or living organisms (Corell et al. 2012), as well as for planning rescue operations or finding lost items. Trajectories can be either observed using drifters or floats, or simulated using a computer model of the ocean and a trajectory algorithm. Model-simulated trajectories may be used to track entire water masses (Döös 1995; Blanke and Raynaud 1997; Döös et al. 2004), or to map transport and dispersion in the ocean (Pizzigalli et al. 2007). As these studies become more frequent, the need for evaluating the modelled results against observations is continuously growing.

In the World Ocean, several studies have used surface drifters or floats to validate model-simulated trajectories. These studies have covered, e.g., the North Atlantic (Garraffo et al. 2001; McClean et al. 2002; Lumpkin et al. 2002), the Pacific (Garfield et al. 2001), and the global ocean (Döös et al. 2011). Although they have employed different models, and different sets of Lagrangian observations, a common conclusion is that the squared displacement from the initial position (the absolute dispersion) shows a fair agreement between models and observations. Discrepancies between them are often found when studying the squared distance between two initially paired drifters (relative dispersion), and/or the variability of the currents (eddy kinetic energy). Relative dispersion and/or eddy kinetic energy is found too low ${ }^{1}$ in models of resolution $1 / 4^{\circ}-1^{\circ}$, thus the simulated drifters do not separate as much as the observed ones (Lumpkin et al. 2002; McClean et al. 2002; Döös et al. 2011).

Discrepancies between models and observations can partly be attributed to the coarse model resolution, which does not take turbulence on small scales into account, and implies a need for parameterizing subgrid-scale motions (Döös et al. 2011; Griffa et al. 2004). For example, an extensive analysis of the performance of six circulation models was performed for the Gulf of Finland (Myrberg et al. 2010). Errors in the wind forcing can also explain some of the differences in some models, e.g., Keevallik and Soomere (2010) highlighted systematic bias between modelled and measured wind directions and air flow properties in the central part of the Gulf of Finland.

To be able to implement realistic parameterizations of subgrid turbulence it is crucial to understand the circulation on small scales. For the Baltic Sea, there have been several studies using model-simulated trajectories (Döös et al. 2004; Soomere et al. 2010; Corell et al. 2012), but very little observational Lagrangian data. To the authors' knowledge, there has been only one experiment using Surface Velocity Program (SVP) drifters similar to the ones used in this study (Håkansson and Rahm

\footnotetext{
${ }^{1}$ The notion 'too low' is used here to denote the situation when a modelled quantity is systematically smaller than its values estimated from measurements. Similarly, the notion 'too high' or 'too large' denotes the case when a modelled quantity systematically exceeds its measured values.
} 
1993; Launiainen et al. 1993). These drifter data sets have not been used to evaluate the accuracy of any ocean circulation model. This lack of observations can, at least partly, be explained by the small horizontal extent over which the depth of the Baltic Sea exceeds the depth of the SVP drifter drogue (which sits between 12 and $18 \mathrm{~m}$ depth), and by the heavy ship traffic. The risk of a surface drifter getting caught up in too shallow waters or colliding with a ship is likely higher in the Baltic Sea than in the open ocean.

For the Baltic Sea, only a few short-term drifter experiments have been performed in the uppermost 1-2 m thick layer. For instance, shallow drifters have been used to validate the output of the High Resolution Operational Model of the Baltic Sea (HIROMB) and to study ice drift in the Gulf of Finland (Kõuts et al. 2010). Also, experiments targeting at the validation of the Seatrack Web oil spill model were performed with the same drifters in the middle of the Gulf of Finland, western Estonian archipelago and in the eastern sector of the Northern Gotland Basin (Verjovkina et al. 2010). Their duration ranged from 8 hours up to 7 days. The longest distance covered by a drifter during a single experiment was 52 nautical miles.

This chapter presents an overview of results of experiments with SVP surface ${ }^{2}$ drifters and shallow ( $\sim 1.5 \mathrm{~m}$ deep) drifters (called GPS/GSM drifters below) deployed in the Baltic Sea in 2010-2011. The advection of SVP drifters has also been simulated using a regional ocean model and a trajectory code. The drifter observations and model trajectories were compared using several statistical measures. Results from the comparison may then be applied to tune the algorithms used to simulate the trajectories to obtain a better fit to observations. The realism of the original and tuned model trajectories is discussed, as well as the implications for Lagrangian modelling in the Baltic Sea. We also present results of a series of experiments with the GPS drifters in the Gulf of Finland that were designed to quantify the spreading of floats' pairs in the uppermost 1-1.5 m thick layer. This behaviour is discussed in the context of predictions from the turbulence theory.

\subsection{Surface Drifters in the Baltic Sea}

Twelve SVP-B (Surface Velocity Program, with barometer port) drifters (Lumpkin and Pazos 2007) were deployed in the Baltic Sea in 2010-2011 (Kjellsson and Döös 2012). Their drift was tracked over the time interval of 14 July 2010-19 November 2011. The drifters were manufactured by Marlin-Yug Ltd. in Sevastopol, Ukraine, and are approved by the Naval Oceanographic Office (NAVOCEANO) to comply with the World Ocean Circulation Experiment (WOCE) type. SVP-B drifters are equipped with a surface buoy containing GPS-sensors for measuring the position, sea surface temperature and atmospheric pressure, and a system to transmit the data to the Argos or Iridium satellites. Attached to the surface buoy is a holey sock anchored between 12 and $18 \mathrm{~m}$ depth. This configuration allows for the drifters to

\footnotetext{
${ }^{2}$ They actually follow subsurface currents at depths $12-18 \mathrm{~m}$.
} 


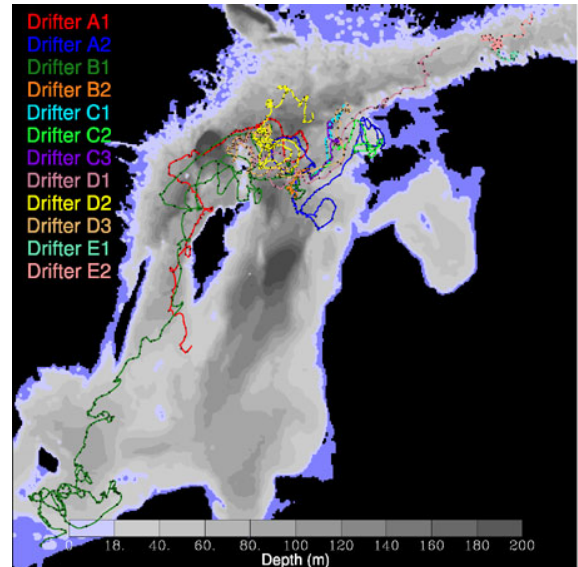

a)

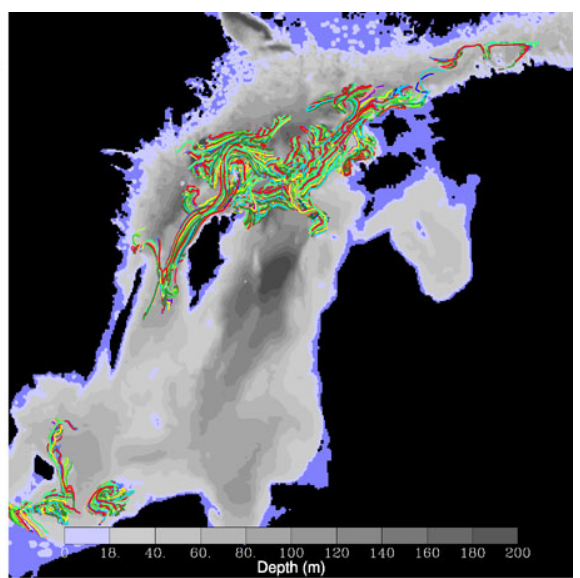

b)

Fig. 8.1 (a) The 12 SVP-B surface drifters used in this study mapped on top of the bathymetry (Kjellsson and Döös 2012). Dots indicate the start of a segment of the drifter's trajectory after every 256 hours. Surface drifters are given a letter corresponding to the deployment event. $A$ and $B$ are the two pairs deployed in 2010, $C$ and $D$ the two triplets in 2011, and $E$ is the pair deployed in 2011 in the Gulf of Finland. (b) Simulated segments of SVP drifters' trajectories. 36 simulated segments were released for each SVP drifter segment except those during the winter (DecemberJanuary-February) season. Depth $<18 \mathrm{~m}$ is indicated by cyan shading

mostly follow subsurface currents at these depths. A schematic picture of the SVP drifters can be found in Lumpkin and Pazos (2007). Data-including the state of the drifter-are transmitted once an hour. The position data retrieved from the Argos and Iridium satellites allows for the identification and elimination of any (occasional) erroneous GPS positions. Our data set did not contain any erroneous positions.

Two pairs of SVP drifters were deployed in the Baltic Sea in July and August 2010 (Fig. 8.1a and Table 8.1). The deployment point was chosen to be near the major fairway where an oil spill could potentially occur. A triplet of drifters was then deployed at the same point in June 2011. As four of these seven SVP drifters got lost (apparently owing to collisions with ships) within a relatively short time period, another triplet was deployed at some distance to the northwest of the previous location in August 2011. Two of the drifters from the two pairs stranded and were then re-deployed as a third pair in the Gulf of Finland in November 2011. All deployments, except the last pair, were made from the ferry Silja Festival on her regular crossing from Stockholm to Riga.

Drifters of a different kind were deployed in the Gulf of Finland to study pair separations in the uppermost layer (Soomere et al. 2011). These drifters were not of the WOCE standard. They were fixed within the uppermost $\sim 1.5 \mathrm{~m}$ thick layer. The active component (a high sensitivity $(-159 \mathrm{~dB})$ GPS/GSM device CT-24, Sanav Corp., Taiwan) of these lightweight floating buoys reported its position 4 times an hour. The device was mounted on the top of a $2 \mathrm{~m}$ long and $50 \mathrm{~mm}$ in diameter 
Table 8.1 The first transmitted positions ( $\sim$ release positions) of all 12 SVP surface drifters, and their lifetime

\begin{tabular}{llll}
\hline Drifter & Initial Lon/Lat & Start date & Lifetime \\
\hline$\# 1$ & $20.6984^{\circ} \mathrm{E} / 58.3559^{\circ} \mathrm{N}$ & 14 July 2010 & 96 days \\
$\# 2$ & $20.6988^{\circ} \mathrm{E} / 58.3562^{\circ} \mathrm{N}$ & 14 July 2010 & 102 days \\
$\# 3$ & $20.6967^{\circ} \mathrm{E} / 58.3568^{\circ} \mathrm{N}$ & 17 August 2010 & 317 days \\
$\# 4$ & $20.6971^{\circ} \mathrm{E} / 58.3567^{\circ} \mathrm{N}$ & 17 August 2010 & 11 days \\
$\# 5$ & $20.7002^{\circ} \mathrm{E} / 58.3539^{\circ} \mathrm{N}$ & 9 June 2011 & 22 days \\
$\# 6$ & $20.6976^{\circ} \mathrm{E} / 58.3532^{\circ} \mathrm{N}$ & 9 June 2011 & 63 days \\
$\# 7$ & $20.6987^{\circ} \mathrm{E} / 58.3539^{\circ} \mathrm{N}$ & 9 June 2011 & 25 days \\
$\# 8$ & $19.8129^{\circ} \mathrm{E} / 58.8452^{\circ} \mathrm{N}$ & 10 August 2011 & 101 days \\
$\# 9$ & $19.8128^{\circ} \mathrm{E} / 58.8447^{\circ} \mathrm{N}$ & 10 August 2011 & 100 days \\
$\# 10$ & $19.8096^{\circ} \mathrm{E} / 58.8462^{\circ} \mathrm{N}$ & 10 August 2011 & 101 days \\
$\# 11$ & $24.7421^{\circ} \mathrm{E} / 59.6804^{\circ} \mathrm{N}$ & 7 November 2011 & 12 days \\
$\# 12$ & $24.7415^{\circ} \mathrm{E} / 59.6796^{\circ} \mathrm{N}$ & 7 November 2011 & 12 days \\
\hline
\end{tabular}

plastic pipe, about $2 / 3$ of which was submerged and about $1 / 3(60 \mathrm{~cm})$ was above the water surface. A picture of one of the drifters can be found in Soomere et al. (2011). Three deployments were made with altogether 8 drifters. Each time drifters were deployed at a distance of about 50-150 m from each other and let to drift from a few days to a few weeks. Two deployments took place about $8 \mathrm{~km}$ west of the island of Naissaar and one in Muuga Bay.

\subsection{Simulated Drifters}

Simulated drifters were computed using the Lagrangian trajectory code TRACMASS (see Chap. 7 and Döös 1995; Blanke and Raynaud 1997) and velocity fields from the Rossby Centre regional Ocean climate (RCO) model (Meier et al. 1999, 2003). The RCO model (Chap. 4) is a coupled ice-ocean circulation model, and a regionalized version of the global Ocean Circulation and Climate Advanced Model (OCCAM) (Webb et al. 1997). Here, the model grid covers the Baltic Sea with an open boundary at Kattegat. The resolution is $1 / 15^{\circ} \times 1 / 30^{\circ}$, i.e., $\sim 2$ nautical miles, with 41 vertical levels, where each layer in the upper $40 \mathrm{~m}$ is $3 \mathrm{~m}$ thick. RCO uses a $k-\varepsilon$ mixing scheme (Meier et al. 2003) to simulate effects of subgrid turbulence, which applies to both velocity components $(u, v)$ in the momentum equations and tracers (temperature, salinity, etc.).

The ocean model RCO and the atmospheric model RCA (Kjellström et al. 2005) are both components of the regional coupled atmosphere-ocean model RCAO (Döscher et al. 2002) that is used for simulating the future climate over Scandinavia. 
In our data set, the RCO model has been run in hindcast mode using atmospheric forcing from the ERA-40 reanalysis (Uppala et al. 2005) and observed river runoff. The ERA-40 fields have been downscaled to the RCO model grid by using them as input for the regional atmospheric model RCA. Winds have subsequently been corrected to include some gustiness (Höglund et al. 2009). Several studies have validated the RCO model output data against observations of temperature, sea surface height, and salinity. Meier (2002) used data from four separate stations in the Baltic Sea, and found that the model data agreed reasonably well. See Chap. 4 for a detailed overview of many features of this model. In the present study, the output data of the RCO model, including temperature, salinity, and three-dimensional (3D) velocity, were available every 6 hours for June 1961-May 2005.

The TRACMASS trajectories are computed off-line, that is, after the fields from the RCO model have been integrated and stored. This allows for faster and less memory consuming computations. A thorough discussion of the pro's and con's of the on-line and off-line methods of trajectory calculations is presented in Chap. 7. The simulated trajectories were not fully Lagrangian: to mimic the motion of the drifters, only horizontal components of the velocities were used to calculate the advection of the particles. The velocity of advection was evaluated as a weighted average of the modelled currents for depths between 12 and $18 \mathrm{~m}$. The simulated drifters were locked at the depth of $15 \mathrm{~m}$. To simulate (the impact of) drifter stranding, any model drifter that at some time instant reached a depth shallower than $18 \mathrm{~m}$ was considered as stranded and the relevant data was removed from the statistics.

The TRACMASS code includes tunable parameterizations of subgrid-scale turbulence and diffusion to imitate subgrid-scale motions (Döös and Engqvist 2007; Döös et al. 2011). The turbulence scheme adds a random perturbation to the velocity fields, while the diffusion scheme adds a random perturbation to the position. In the zonal direction, the impact of turbulence is included as

$$
\begin{aligned}
& u_{\text {new }}=u_{\text {orig }}+u_{\text {turb }} \\
& u_{\text {turb }}=\kappa \frac{1}{\left(\Delta t_{\text {min }}\right)^{1 / 3}}(q-0.5) u_{\text {orig }},
\end{aligned}
$$

where $q$ is a random number between 0 and 1 . The same value of $q$ is used at both the eastern and western grid box walls. The quantity $\Delta t_{\min }$ is the time until the trajectory has moved through the grid box or until the velocity fields are updated (every hour) and may therefore be individual for each trajectory (see Chap. 7 for details). There is thus no uniquely defined time step of the 'upgrade' of the velocity or position in the parameterization of turbulence or diffusion. The random increment added by the turbulence scheme is proportional to the mass flux through the grid box, the time step, a random number, and a parameter $\kappa$. The equations are similar in the meridional direction.

The value of the parameter $\kappa$ was set by simulating trajectories with no turbulence parameterization and comparing the results to observed SVP drifters. An empirical value can then be estimated by simulating trajectories using different $\kappa$ and comparing to observed drifter trajectories. 
The scheme is a low-order one in the sense that it does not take into account properties such as Lagrangian time scales or Lagrangian velocity autocorrelation. Schemes like this are often called 'Markov 0' processes (Rupolo 2007). Several more advanced processes of 'Markov 1' or 'Markov 2' type have been tested in other studies but never used with the TRACMASS code, and thus are not used in this study. The possible advantages of using Markov 1 or Markov 2 models will be discussed in Sect. 8.9.

\subsection{Lagrangian Statistics}

Absolute dispersion is a measure of the square of travelled distance from the origin, i.e., the trajectory length, as a function of time. An average of this quantity over $M$ trajectories is here evaluated by integrating the velocity

$$
D_{A}^{2}\left(t_{n}\right) \equiv \frac{1}{M} \sum_{m=1}^{M}\left(\int\left|u_{i, m}\left(t_{n}\right)\right| d t\right)^{2}
$$

where $t_{n}$ is the time (discrete steps), $d t$ is the time step ( 1 hour in experiments with the SVP drifters), $m$ is the trajectory number, and $i$ indicates which velocity component is used. The turbulent absolute dispersion, $D_{A}^{2^{\prime}}\left(t_{n}\right)$ is found by integrating the turbulent velocity $u^{\prime}=u-\bar{u}$, where $\bar{u}$ is a time average of the trajectory, in a similar fashion. The mean displacement is defined as the displacement from the origin as a function of time

$$
D_{D}\left(t_{n}\right) \equiv \frac{1}{M} \sum_{m=1}^{M} \sqrt{\sum_{i=1}^{2}\left[x_{i, m}\left(t_{n}\right)-x_{i, m}(0)\right]^{2}},
$$

where $t=0$ is associated with the beginning of a trajectory segment.

Relative dispersion is often defined as the square of the distance from the mean position at a certain time. However, here it is defined as half of the pair separation, i.e., the square of half of the distance between two drifters at a given time step, which is equal to the squared distance from the mean position of the two drifters. With the same notations as for the absolute dispersion, the average relative dispersion over $P$ pairs is defined as

$$
D_{R}^{2}\left(t_{n}\right) \equiv \frac{1}{P} \sum_{p=1}^{P} \sum_{i=1}^{2}\left(\frac{d_{i, p}\left(t_{n}\right)}{2}\right)^{2}, \quad d_{i, p}\left(t_{n}\right)=x_{i, q}\left(t_{n}\right)-x_{i, r}\left(t_{n}\right),
$$

where $d_{i, p}$ is the pair separation and $p$ is the pair consisting of drifters $r$ and $q$. The square of the separation ensures positive values.

The Lagrangian velocity is obtained by using a non-centred finite difference scheme

$$
u_{i, m}\left(t_{n}\right) \equiv \frac{d x_{i, m}\left(t_{n}\right)}{d t} \approx \frac{x_{i, m}\left(t_{n}\right)-x_{i, m}\left(t_{n-1}\right)}{t_{n}-t_{n-1}}
$$


with the indices having the same meaning as above. Similarly, the acceleration was calculated using a similar finite difference scheme applied to the particular velocity component:

$$
a_{i, m}\left(t_{n}\right) \equiv \frac{d u_{i, m}\left(t_{n}\right)}{d t} \approx \frac{u_{i, m}\left(t_{n}\right)-u_{i, m}\left(t_{n-1}\right)}{t_{n}-t_{n-1}} .
$$

Note that velocity is not defined at the first time instant (or position), and acceleration is not defined at the first and second time instant.

The Lagrangian velocity autocorrelation describes the correlation of the velocity at one time with that of previous times:

$$
R(\tau)=\frac{\sigma^{2}(\tau)}{\sigma^{2}(\tau=0)} \approx R_{q}=\frac{\sigma_{q}^{2}}{\sigma_{0}^{2}}
$$

where $\sigma^{2}(\tau)$ and $\sigma^{2}(\tau=0)$ are the Lagrangian velocity autocovariances for time lag $\tau$ and no lag ( $\tau=0$ ), respectively. Here $q$ is the discrete time step and $R_{q}$ is the autocorrelation at time step $q$. The quantity $\sigma^{2}(\tau)$ is defined as

$$
\sigma^{2}(\tau)=\lim _{T \rightarrow \infty} \frac{1}{T} \int_{0}^{T} \mathbf{u}^{\prime}(t+\tau) \cdot \mathbf{u}^{\prime}(t) d t \approx \sigma_{q}^{2} \equiv \sum_{i=1}^{2} \frac{1}{N-q-1} \sum_{n=1}^{N-q-1} u_{i, n}^{\prime} u_{i, n+q}^{\prime},
$$

where $u_{i, n}^{\prime}=u_{i, n}-\bar{u}_{i}$ and $\bar{u}_{i}$ is a time average of the segment. Note that the total velocity autocovariance is the sum of its zonal and meridional components: $\sigma^{2}=$ $\sigma_{i=1}^{2}+\sigma_{i=2}^{2}$.

Using the autocorrelation $R(\tau)$, the Lagrangian integral time scale $T_{L}$ is defined as

$$
T_{L}=\int_{0}^{t_{1}} R(\tau) d \tau
$$

This is a measure of the memory of a trajectory, that is, the time lag during which the Lagrangian velocity is correlated. When computing this integral, the upper bound, $t_{1}$, is the point where $R(\tau)=0$ occurs for the first time. This truncation is perhaps the most commonly used one, due to the often noisy character of the autocorrelation function $R(\tau)$ for large $\tau$. Lumpkin et al. (2002) compared this choice with several other approximations, and found that all approaches produced essentially the same results. Thus it is natural to assume that the approximation used here is a robust one.

\subsection{Results}

\subsubsection{The Surface Drifters}

The 12 drifter trajectories were of different length because of variable drifter lifetime. The mean drifter lifetime was $\sim 80$ days (Table 8.1 ). For this reason, each 
Fig. 8.2 Pair separation (distance between drifters) for each individual drifter pair

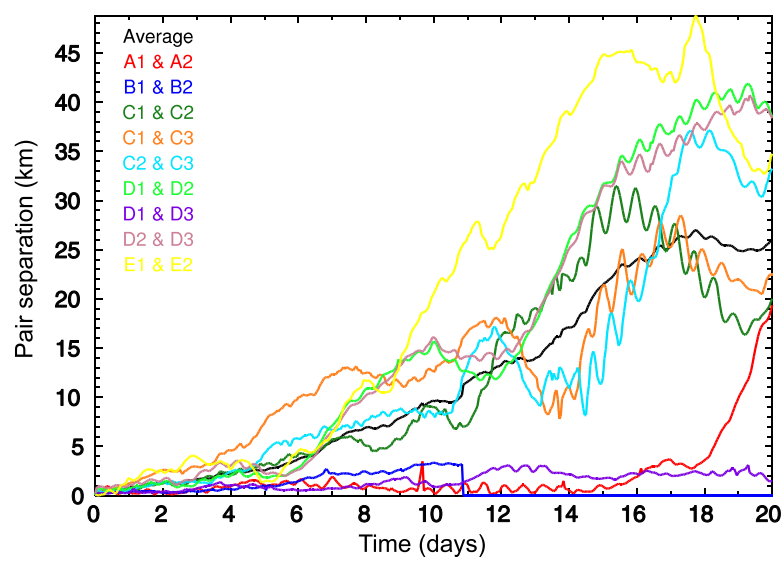

drifter trajectory was split up into shorter segments of fixed length (called SVP segments or simply segments below). To make the Fast Fourier Transformation (FFT) calculations more convenient, the segments' length was taken as a power of two, $2^{8}=256$ hours. It was important that the segments (i) were long enough for consecutive segments of each trajectory to be uncorrelated (this property will be discussed later) and (ii) yield a reasonably long time series of single-particle statistics. They also needed to be shorter than the shortest SVP drifter trajectory ( $\sim 11$ days). This resulted in 85 segments altogether. From our viewpoint of statistical properties of dispersion these segments can be interpreted as trajectories of 85 independent drifters.

Tracks of the SVP drifters are shown in Fig. 8.1a. The drifter deployments yielded 9 pairs (Fig. 8.2). It should be noted that the pair separation (related to relative dispersion by Eq. (8.5)) grew at very different rates and that the pairs had very different lifetimes. For instance, the pair 'E1 \& E2' dispersed rapidly after 5 days, while the pair 'D1 \& D3' stayed essentially paired for more than 20 days.

Velocities at each time step, except for the last one, were calculated for each SVP drifter from Eq. (8.6). The drifter velocities show strong currents near Poland, west of Estonia and west of Gotland (Fig. 8.3a). The Lagrangian time scales computed for each segment from Eq. (8.10) are shown in Fig. 8.3b. In this case, the turbulent velocities were calculated by subtracting the time-averaged velocity of the segment, not the full trajectory. A comparison of Figs. 8.3a and 8.3b shows that regions of high velocity tend to have higher frequencies of variability, and thus shorter Lagrangian velocity time scales. Note that the relevant time scales are $\sim 1-2$ days, similar to those calculated from SVP drifters in other parts of the World Ocean (Rupolo 2007), and much shorter than the segment length.

The SVP drifters also collected data of sea surface temperature (Fig. 8.4) and atmospheric pressure. During summertime temperatures reached $\sim 24{ }^{\circ} \mathrm{C}$, while descending to near $0{ }^{\circ} \mathrm{C}$ in winter. The only SVP drifter surviving the winter always measured temperatures above $0{ }^{\circ} \mathrm{C}$. By using available ice charts it was verified that the drifter avoided ice-covered waters. 


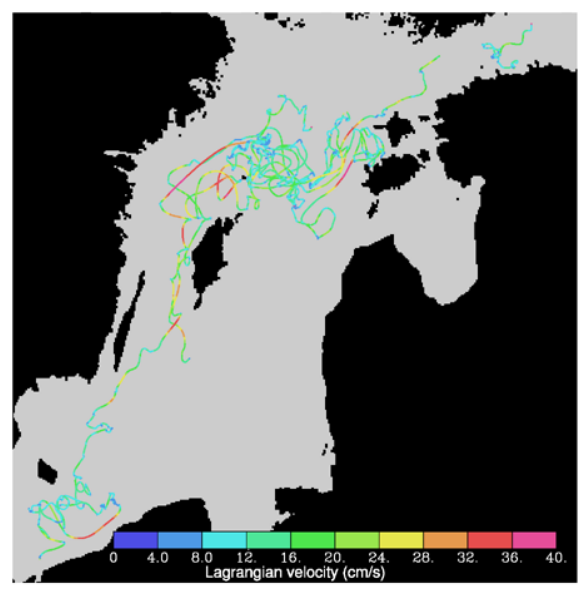

a)

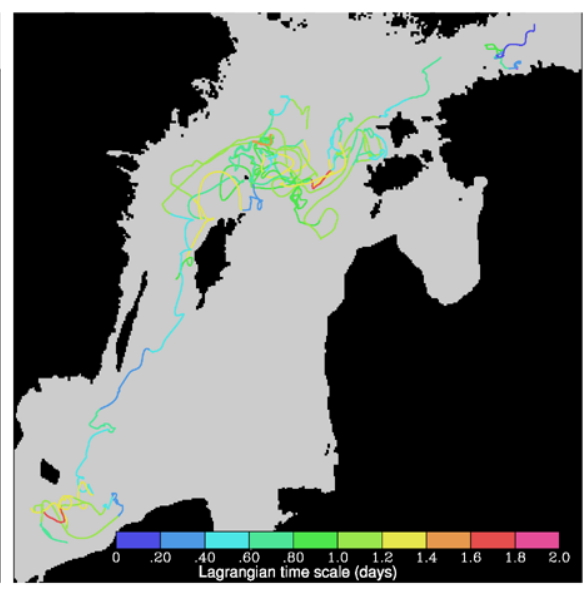

b)

Fig. 8.3 (a) SVP drifter trajectories coloured by their total Lagrangian velocities. The colour range is from 0 to $0.4 \mathrm{~m} / \mathrm{s}$. (b) SVP drifter trajectories coloured by the Lagrangian integral time scales. Calculations of Lagrangian time scales yielded one value per drifter segment (256 hours). Colours range from 0 to 2 days

Fig. 8.4 The sea surface temperature measured by each SVP drifter. Horizontal time axis is days from the first deployment, 14 July 2010, up to December 2011 when the data collection was stopped. The SSTs were constantly above $0{ }^{\circ} \mathrm{C}$, suggesting ice-free conditions

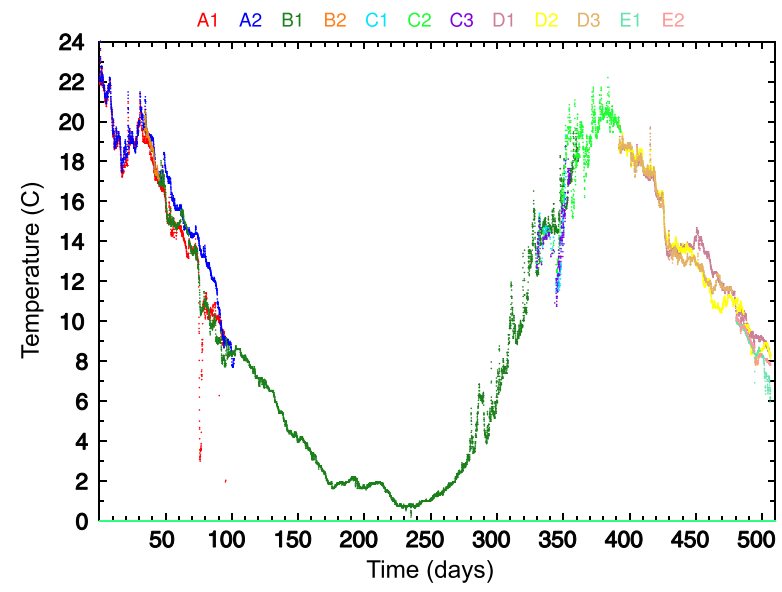

\subsubsection{Model Evaluation}

The years 2010-2011 were not available in our RCO data set and thus a direct comparison of measured and modelled statistical features of drift was not possible. Also, the first and last years (1961 and 2005) in the RCO data set were incomplete and could therefore not be used. Statistics extracted from the SVP drifter segments was therefore compared to statistics derived from the motion of simulated drifters in 1962-2004. This comparison is not exactly straightforward because the SVP drifter data in 2010-2011 were collected under ice-free conditions but large parts of the 
Baltic Proper ${ }^{3}$ and the Gulf of Finland have been frozen during some winters in 1962-2004. The presence of ice definitely impacts both the modelled and real velocity fields but in our comparison the related effects only become evident for simulated drifters (assuming that the RCO model simulated the sea ice correctly). Including simulated winter drifters in some ice-free years while excluding those from years of a frozen Baltic Sea would give extra weight to some years in the statistics and would thereby bias the comparison. For this reason, all segments recorded by the SVP drifters during the period December 2010-February 2011 were removed from the data, leaving 76 drifter segments for the comparisons with the modelled data.

The starting longitude and latitude as well as hour, day, and month for each of the 76 drifter segments were used as starting points for simulated drifters in each full model year (1962-2004). Thus, 36 simulated drifters were released around each starting point in each model year, resulting in $36 \times 76=2736$ segments for each model year. Four of the 36 simulated drifters around each starting point originated in the same grid box as the surface drifter segment, while the others were spread horizontally in the eight adjacent grid boxes.

As each grid box was about two nautical miles wide, the described process converted each starting point of a SVP drifter segment into a 'cloud' (with a radius of about 3 nautical miles or $\sim 5.5 \mathrm{~km}$ ) of model drifters. Doing so made it possible to take into account the natural subgrid-scale variability of currents around the starting point of each drifter. The large number of simulated drifters also resulted in clearer statistics. In an additional experiment, the number of simulated drifters was doubled, resulting in no significant difference in the statistical parameters. It was thus concluded that the set of 36 simulated drifters per each SVP drifter formed a sufficient pool of samples to calculate the necessary statistics. No turbulence or diffusion parameterization was used at this point. In order to better replicate the conditions of the motion of SVP drifters, the advection of the simulated ones was calculated using the horizontal velocities at $12-18 \mathrm{~m}$ depth, with no vertical velocity. Moreover, only simulated drifters that stayed for 256 hours in waters deeper than $18 \mathrm{~m}$ were used in the comparison. Simulated drifter segments from the year 1962 (Fig. 8.1b) covered similar sea regions as the SVP drifter segments but their separation rate was smaller.

The positions of simulated drifters were stored every hour to have the same temporal resolution as for the SVP drifters. However, the velocity fields from the RCO model were only available every 6 hours. Hence, variations on time scales shorter than 12 hours were not resolved by the model, and time scales slightly longer were poorly resolved. The average velocity power spectrum of all SVP drifter segments (Fig. 8.5, left panel), shows a peak near the frequency of 2 cycles per day, corresponding to a period of $\sim 14$ hours. This peak obviously reflects the presence of inertial oscillations (see Chap. 2, Sect. 2.3.4 for details).

While this peak was very pronounced for the SVP drifters, it was also visible for the pool of all simulated drifters in each model year but in this case appeared as a double peak. This distortion is most likely an effect of the inertial oscillations

\footnotetext{
${ }^{3}$ We use here the notion Baltic Proper to denote the Eastern, Northern and Western Gotland Basin, Bornholm Basin and Gdańsk Bay (Chap. 2, Fig. 2.1).
} 


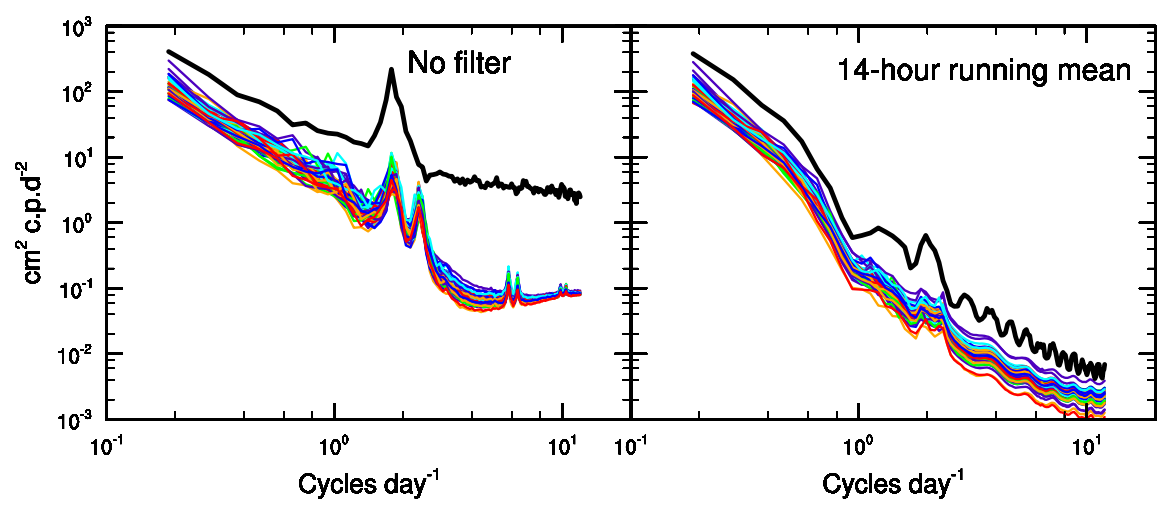

Fig. 8.5 Power spectra of the Lagrangian velocity for SVP drifters (thick black line) and simulated drifters in each year 1962-2004 (thin coloured lines) for the unfiltered data (left) and with a 14-hour running mean applied to both SVP and simulated drifter positions (right)

being poorly resolved, leading to aliasing (errors in the frequency). It is very likely that similar distortions occurred in the statistics of trajectories simulated using the RCO velocity fields in Chaps. 9 and 10. In order to remove the distorted part of statistics, a 14-hour running mean was applied to the drifter positions of both the SVP and modelled drifters before further processing of the data. After filtering out the inertial oscillations the power spectra for the SVP and simulated drifters were quite similar (Fig. 8.5, right panel).

The mean displacement was calculated for both SVP drifter segments and simulated drifters using Eq. (8.4). The procedure yielded one time series for all SVP drifter segments and one for each model year (1962-2004) (Fig. 8.6c). The total and turbulent components of absolute dispersion (Eq. (8.3)) were also calculated (Figs. 8.6a, b). The absolute dispersion increased with time during the entire duration of the segments, while the mean displacement started to level off at the end of the segments ( $\sim 10$ days). This indicates that the horizontal extent over which the mean depth is $>18 \mathrm{~m}$ in the Baltic Sea is rather small, and that drifters can only drift for $\sim 40 \mathrm{~km}$ until they become influenced by this.

The discrepancies between observed and simulated drifters in Fig. 8.6 indicate that the simulated velocities are lower than the observed ones. Indeed, the distribution of absolute velocities for all drifter segments, and for all simulated drifters in each model year (Fig. 8.7) showed the latter to be narrower (thus exhibiting less variability) and centred over lower values than the former. Note that there are far more simulated drifters in a given model year than the 76 observed SVP drifter segments. For this reason all the distributions are normalized to have the integral equal to 1 . The results thus suggest that the horizontal velocities in the RCO model generally are lower and less variable than those of the SVP drifters.

Every trajectory is characterized by two Lagrangian velocity autocorrelation functions, one for the zonal and another for the meridional velocity. The total velocity autocorrelation is the average of the two. It was calculated and averaged over all SVP drifter segments and also over all simulated drifters (Eqs. (8.8)-(8.9)) in 


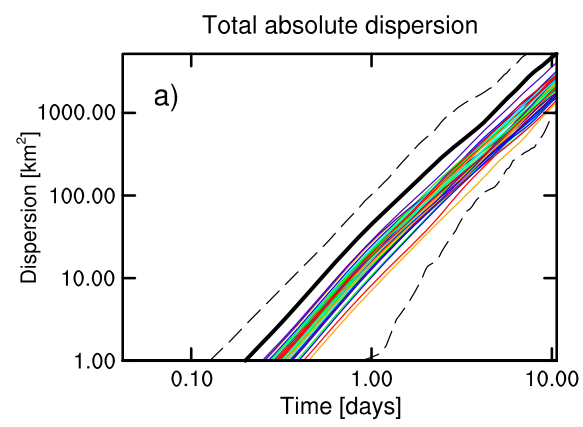

Turbulent absolute dispersion

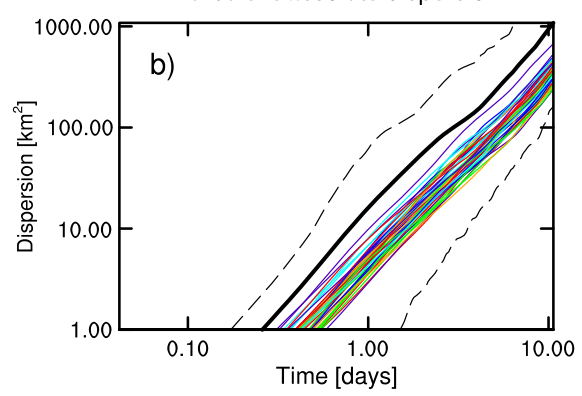

Mean displacement

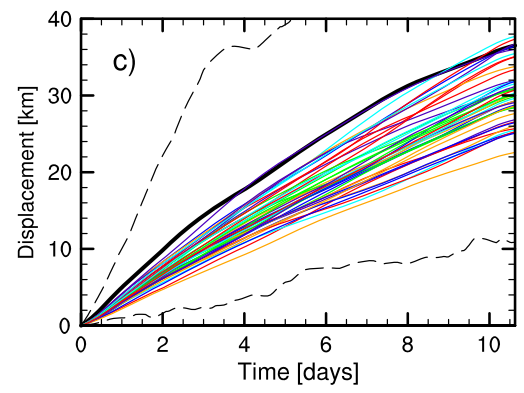

Fig. 8.6 (a) Absolute dispersion by integrating the total velocity $D_{A}^{2}$ on a $\log -\log$ scale; (b) absolute dispersion by integrating the turbulent velocity $D_{A}^{2}$; (c) mean displacement. Solid black lines indicate the ensemble mean for SVP drifter segments, solid coloured lines are ensemble means for simulated segments for each year 1962-2004. Dashed black lines show the 10th and 90th percentiles for SVP drifter segments

Fig. 8.7 Normalized distributions of the total Lagrangian velocities (Eq. (8.6)) for SVP drifter segments (black line) and simulated drifters in all model years (colour lines). The distributions of simulated velocities are narrower and displaced towards lower values than the distribution of SVP drifter velocities

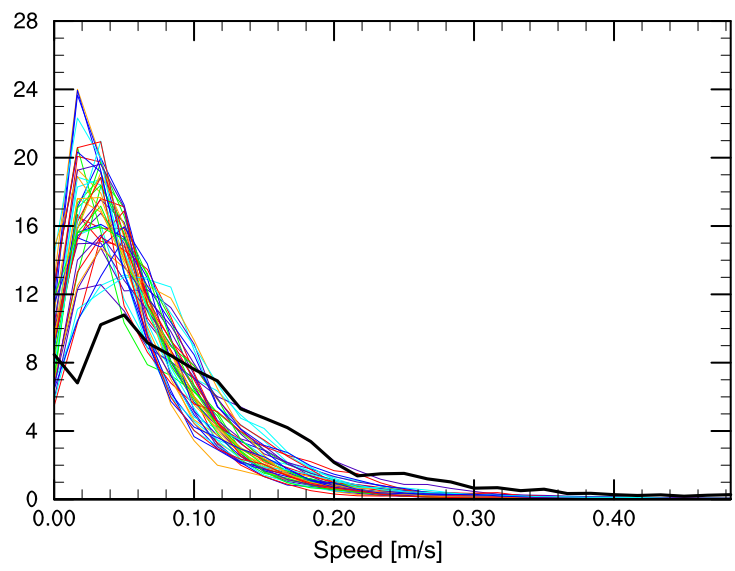

each year (Fig. 8.8). Note that the velocity autocorrelation is normalized autocovariance (Eq. (8.9)) and that the autocovariance is calculated from $u^{\prime}$ and $v^{\prime}$ defined as $u^{\prime}=u-\bar{u}$ and $v^{\prime}=v-\bar{v}$ (Rupolo 2007). 


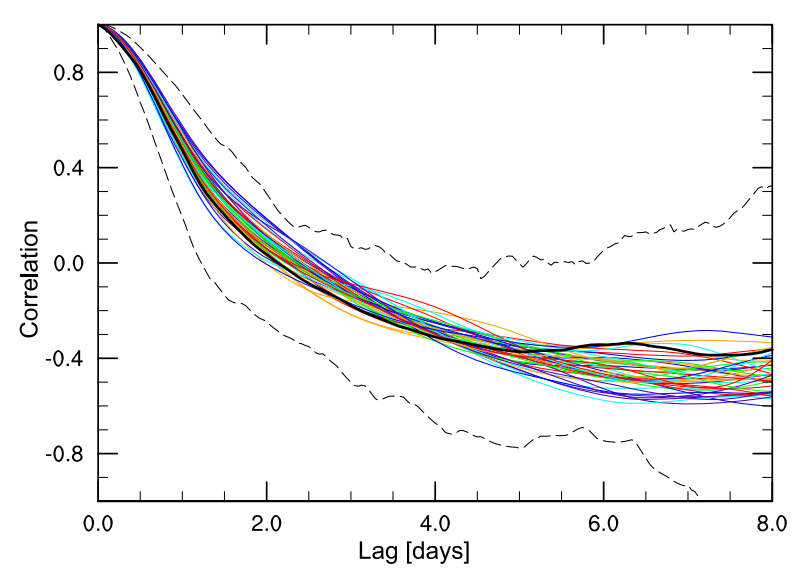

Fig. 8.8 Ensemble-mean Lagrangian velocity autocorrelation $R(\tau)$ for SVP drifter segments (thick black line) and for model trajectories in each model year (colour lines). Dashed lines show the 10th and 90th percentiles of the SVP drifter segments. The horizontal coordinate is the time lag $\tau$ ranging up to 8 days. Note that all trajectories, observed and modelled, were filtered using a 14-hour running mean. The smallest $\tau$ for which $R(\tau)=0$ is the upper limit of the integral in Eq. (8.10)

As noted above, a good agreement between statistical characteristics of simulated and SVP drifter segments was found only after the inertial oscillations had been filtered out with a 14-hour running mean (Fig. 8.8) since the inertial oscillations are poorly resolved in the RCO model output (Fig. 8.5). The Lagrangian integral time scale $T_{L}$ was calculated by integrating the autocorrelations using Eq. (8.10), where the lowest $\tau$ for which $R(\tau)=0$ was used as upper limit of the integral (see Lumpkin et al. 2002 for comments on this, and other, methods). This was done for both zonal and meridional velocity autocorrelations. The total Lagrangian integral time scale is defined as the average of the two time scales. Hence, there was one time scale for each drifter segment.

The distributions of $T_{L}$ for all the SVP drifter segments and simulated drifters in each model year were both centred over time scales $\sim 1$ day (Fig. 8.9). The distributions were normalized as there were more simulated drifters than observed ones. There was good agreement between the drifter data and corresponding model results, largely attributable to the agreement in velocity autocorrelations. This can be interpreted as indicating that the variabilities in the observed and simulated Lagrangian velocities have similar time scales.

The relative dispersion cannot be calculated from the SVP drifter segments since the drifters need to be paired initially. For this reason, only the 12 complete SVP drifter trajectories and the corresponding simulated drifters originating from the starting points of these SVP trajectories were used. Both were filtered with the 14-hour running mean as mentioned before. As each of the SVP drifter pairs was modelled by $2 \times 36=72$ simulated drifters, and each of the triplets using $3 \times 36=108$ simulated drifters, this yielded 9 pairs of SVP drifters, and 
Fig. 8.9 Normalized distribution of the total Lagrangian integral time scales calculated using the autocorrelations in Fig. 8.8. Shown are SVP drifter segments (thick black line) and simulated drifters (thinner, coloured lines) in each model year

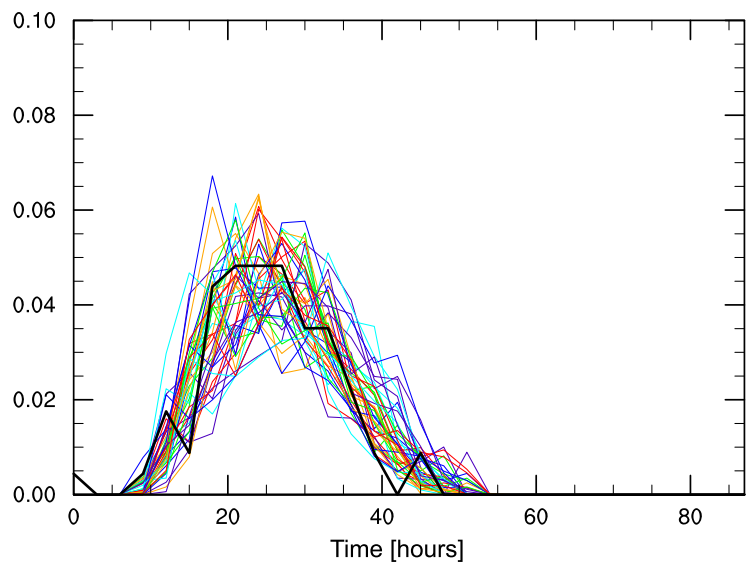

$>5000$ simulated pairs for each model year. The SVP drifters were initially separated by ${ }^{4} \mathcal{O}(100) \mathrm{m}$, but the simulated drifters had an initial separation ranging from $\mathcal{O}(100) \mathrm{m}$ to $\mathcal{O}(1000) \mathrm{m}$ as they were spread more widely around the SVP drifter starting point. Initially, only modelled drifter pairs with initial separation of $<1 \mathrm{~km}$ (equivalently, $D_{R}^{2}(0)<0.25 \mathrm{~km}$ ) were used for the comparison with the SVP drifter pairs.

The relative dispersion was evaluated as an ensemble average over all SVP drifter pairs and also over all simulated drifter pairs for each model year. This quantity was found to be much lower for the simulated pairs of trajectories than for the SVP drifter pairs (Fig. 8.10). Part of this difference may be due to the fact that the RCO model has a resolution of $\sim 5.5 \mathrm{~km}$. Therefore, processes that lead to separation on scales below this value are generally not resolved, and no parameterization of turbulence or diffusion was used. Studies with an OGCM (Poje et al. 2010) have shown that although $D_{R}^{2}$ increases with $t$, the values are generally lower at coarser resolutions, which is consistent with Fig. 8.10. However, in this study, the growth rates of $D_{R}^{2}(t)$ are different for SVP drifters and model drifters, which was not the case when running the OGCM and merely varying the resolution. Hence, the observed difference is due to more than just the coarse resolution of the RCO model.

To check whether or not the moderate resolution of the RCO model is the dominant reason for a too low separation of the modelled pairs, the motions of simulated pairs with an initial separation in the range of 4-12 km (approx. 1 to 3 grid boxes) were also compared to the behaviour of pairs of SVP drifters (Fig. 8.11). The simulated relative dispersion should then be compared to the relative dispersion of SVP drifters after their distance has reached $4 \mathrm{~km}$. This process takes about 9 days. Figure 8.11 shows the relative dispersion as a function of pair separation. Even when the simulated pairs were separated by one grid box, the relative dispersion of mod-

\footnotetext{
${ }^{4}$ The 'Big O' notation is commonly used to describe the limiting behaviour of a function $f$ by comparing it to the behaviour of a simpler function $g$ (Chap. 3). Here we use it to roughly characterize the distance between drifters.
} 

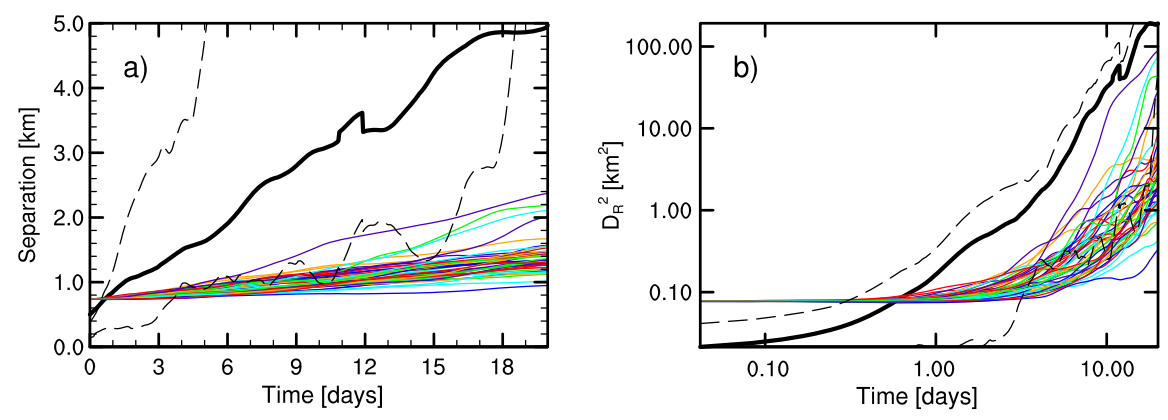

Fig. 8.10 (a) Mean pair separation. (b) Mean relative dispersion. The black solid line shows the mean of all SVP drifter pairs, and the coloured lines show the mean of all simulated pairs in each model year 1962-2004. Dashed lines show the 10th and 90th percentile of the SVP drifter pairs. The initial separation of pairs of both drifters and model trajectories is $\mathcal{O}(100) \mathrm{m}$, that is, much smaller than the model grid box width
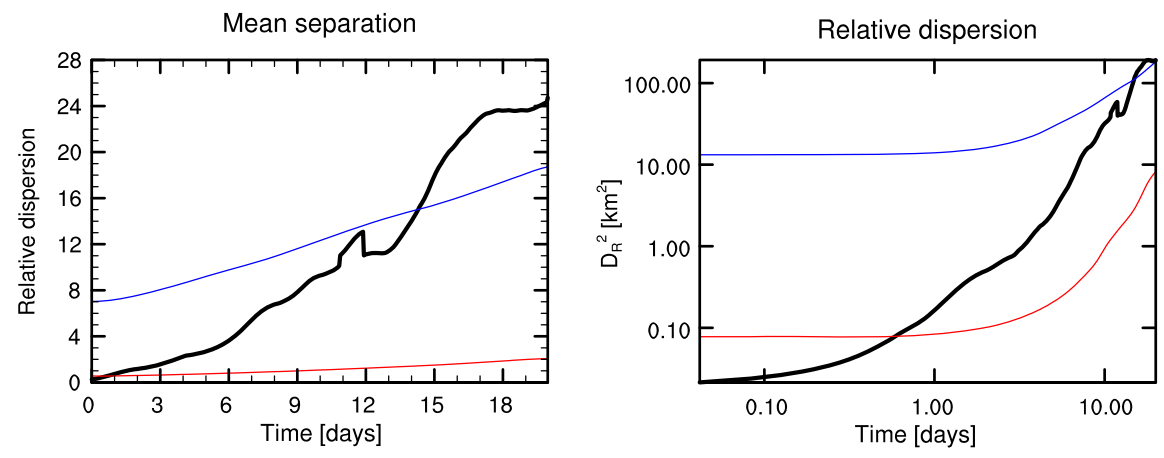

Fig. 8.11 As Fig. 8.10, but an average is calculated of all model years 1962-2004 (red line). The blue line shows the same average of model years, but with drifter pairs initially separated by $>4 \mathrm{~km}$

elled pairs did not agree with that of the SVP drifter pairs. This finding indicates that the discrepancies are not only due to the limited resolution of the RCO model.

\subsection{Tuning the Trajectories}

As previously noted, the simulated velocities of drifters were generally lower and less variable than the observed ones (Fig. 8.7). From Fig. 8.12 the mean displacement $D_{D}$ can be estimated as $\sim 37 \mathrm{~km}$ after 256 hours for the SVP drifter segments. The corresponding average of modelled drifters over all model years is $\sim 30 \mathrm{~km}$ after 256 hours. This indicates that the modelled mean displacement is generally only $4 / 5$ of the observed one.

As a first approximation to resolve this discrepancy, all model velocities were multiplied by 1.25 ( since $(30 / 37) \times 1.25 \approx 1)$ and the simulations of model trajectories repeated. This resulted in the mean displacement and absolute dispersion 

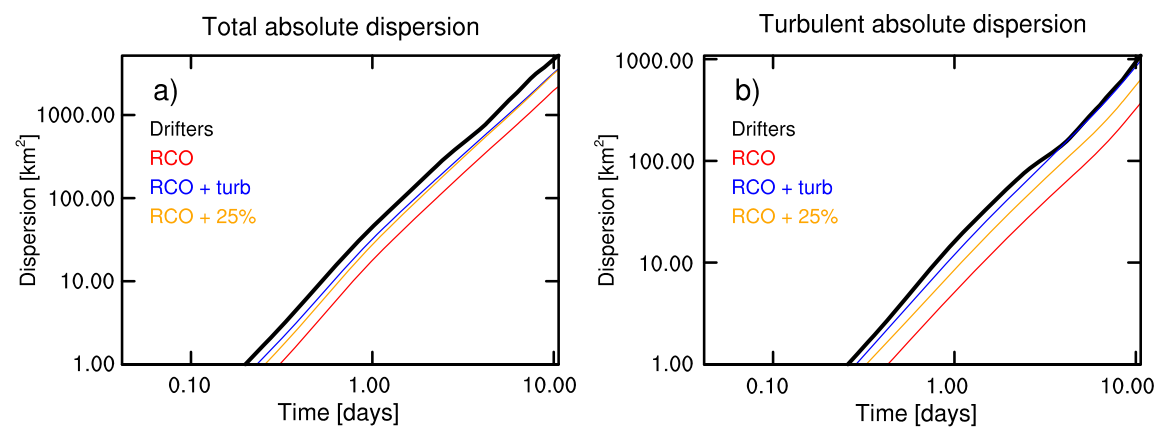

Mean displacement

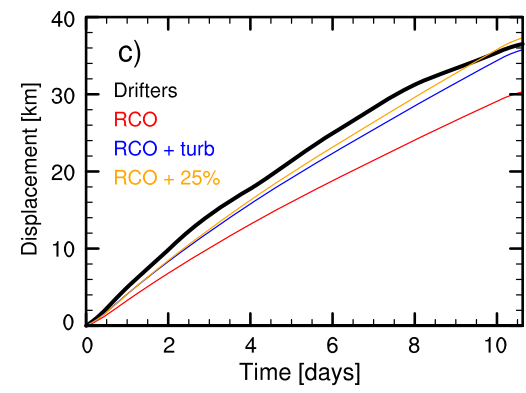

Fig. 8.12 (a) Total absolute dispersion, $D_{A}^{2}$. (b) Turbulent absolute dispersion, $D_{A}^{2 \prime}$. (c) Mean displacement of SVP drifter segments (black), and for all simulated trajectories in all model years 1962-2004 (red). Also shown are the results when including parameterized subgrid turbulence (blue), and when multiplying the modelled velocity fields by 1.25 (yellow)

of the simulated drifters shifted to values closer to those calculated from the drifter segments (Fig. 8.12). This suggests that the simulated velocities were too low in the original RCO simulation. Interestingly, this increase in the velocity magnitude by $25 \%$ did not, however, yield more variability in the motion of modelled drifters.

In another simulation, we employed the turbulence scheme for TRACMASS as introduced in Döös and Engqvist (2007), Döös et al. (2011). This scheme added extra velocity to the simulated drifters, but not necessarily in the direction of the modelled advection. All data was filtered with a 14-hour running mean as before. The magnitude of the subgrid turbulence, controlled by the parameter $\kappa$ in Eq. (8.2), was tuned to get the values of mean displacement close to that of the SVP drifter data. A fair fit was achieved for $\kappa=200$ (Fig. 8.12). This estimate is close to the value of $\kappa$ used in Döös et al. (2011) for the open ocean conditions. For turbulent absolute dispersion $D_{A}^{2 \prime}$ using subgrid turbulence led to better match of the statistics of modelled and SVP drifters than simply multiplying the velocities by 1.25 .

For both above-mentioned methods, the distributions of Lagrangian integral time scales, $T_{L}$, are shown in Fig. 8.13. Note that $T_{L}$ is calculated using the deviations from the time-averaged velocities, $u^{\prime}$ and $v^{\prime}$ defined as $u^{\prime}=u-\bar{u}$ and $v^{\prime}=v-\bar{v}$. The random motions introduced by the subgrid turbulence shortened the Lagrangian integral time scales even though the data was filtered by a 14-hour running mean. 


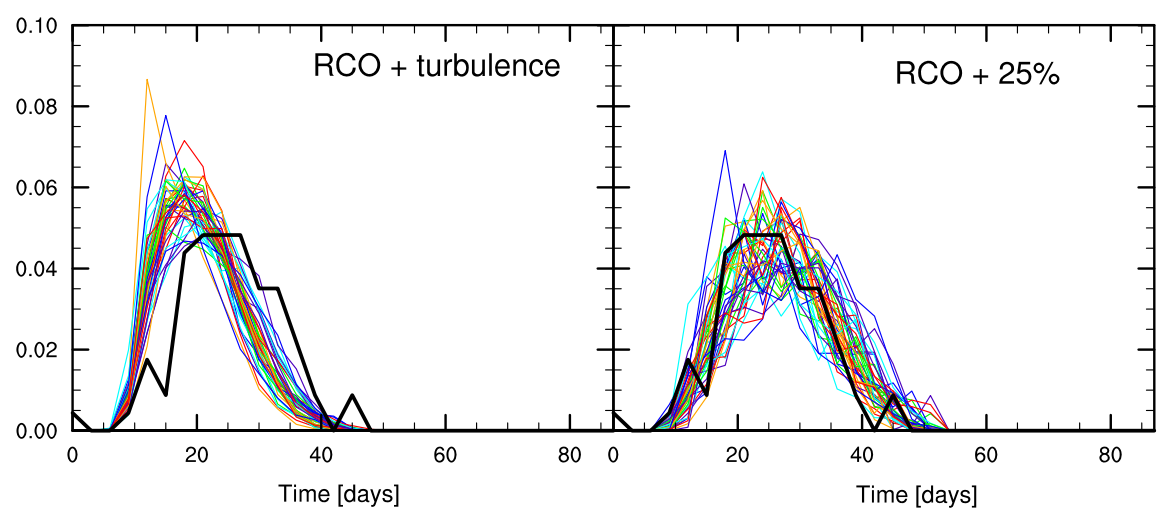

Fig. 8.13 Normalized distribution of the Lagrangian integral time scales for all SVP drifter segments (thick black line) and all simulated trajectories in each model year (thin colour line). Left panel shows for model simulations with added subgrid turbulence of $\kappa=200$, and the right shows model simulations where the horizontal velocities at each point and time step are multiplied by 1.25

This did not occur when the velocities were simply multiplied by 1.25 . The reason is that the latter operation does not introduce any new motion and merely amplifies the advection that is already present, while a 'Markov 0' model has no memory since the turbulence is completely random. As mentioned above, there exist more advanced turbulence parameterizations in other Lagrangian models that account for velocity autocorrelation (e.g., 'Markov 1' and 'Markov 2' type). Such schemes are not available yet in TRACMASS.

The relative dispersion calculated from the motion of trajectories simulated using the two above-described variations of the evaluation of velocities is shown in Fig. 8.14. Multiplying the simulated velocities by a constant factor did not increase the relative dispersion significantly compared to the data presented in Fig. 8.11. Adding subgrid turbulence, however, resulted in an increase of both relative dispersion and pair separation. The resulting values of these quantities were closer to those extracted from the SVP drifter data. For initially close drifters $\left(D_{R}^{2}(0)<0.25 \mathrm{~km}\right)$, adding the parameterization of subgrid turbulence resulted in a good agreement at times $>10$ days (Fig. 8.14). Note, however, that the magnitude of the impact of subgrid processes used in this calculation was chosen to give a good fit for absolute dispersion and mean displacement, and thus some differences in relative dispersion are not unexpected.

\subsection{Spreading Rates in the Uppermost Layer of the Gulf of Finland}

The separation of drifters can be also approximated by a power function or an exponential law of the time $t$ elapsed since the release of the particles. The spreading rate 

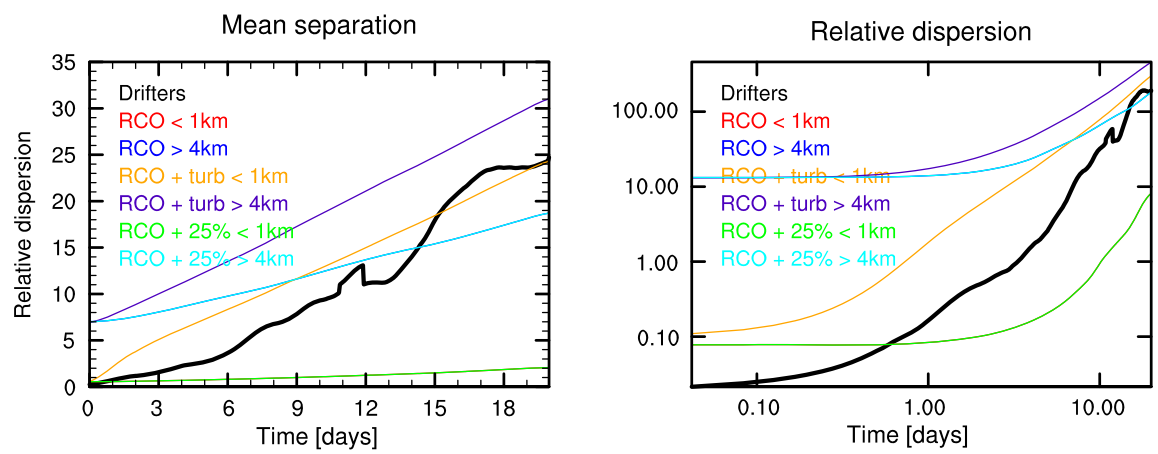

Fig. 8.14 Mean pair separation (left) and relative dispersion (right) for SVP drifter pairs (thick black line), and for all simulated drifters in all model years (colour lines). As in Fig. 8.11, two sets of trajectories are shown for each simulation; those with initial pair separation $<1 \mathrm{~km}$ (red, green, orange) and those with $>4 \mathrm{~km}$ (blue, cyan, purple). The simulations shown are the original (red, blue), one with added subgrid turbulence (orange, purple) and one where all modelled velocities were increased by $25 \%$ (green, cyan). Multiplying the velocity fields by 1.25 does not alter the relative dispersion, so the green and red as well as blue and cyan lines overlap

is then the rate of change of the separation distance with time (and thus related to relative dispersion, see Eq. (8.5)). The classical notion for the average distance between two particles in a turbulent velocity field, Richardson's law (Richardson 1926), applies in fully developed 3D turbulent flows where the average difference between velocity fluctuations $\mathbf{u}(\mathbf{r}, t)$ follows the (Kolmogorov's) power law (Falkovich et al. 2001):

$$
\langle|\mathbf{u}(\mathbf{x}, t)-\mathbf{u}(\mathbf{x}+\Delta \mathbf{x}, t)|\rangle=A|\Delta \mathbf{x}|^{a} .
$$

Here angle brackets denote averaging over the coordinate $\mathbf{x}=(x, y, z)$ and/or over the ensemble of flows, $A$ is a constant and the exponent $a=1 / 3$ is specific to the fully developed 3D turbulent flow. In such an environment, the average distance $d$ between a pair of particles scales as

$$
d \propto t^{b}, \quad \text { where } b=\frac{1}{1-a} .
$$

In the case of Kolmogorov's law $a=1 / 3$, the corresponding exponent is $b=3 / 2$.

The character of spreading is markedly different in two-dimensional (2D) flows where, at scales smaller than the energy input scale, the velocity spectrum is dominated by the enstrophy cascade and $a=1$. In this situation the exponent $b \rightarrow \infty$ in Eq. (8.12) and an exponential growth of the distance with time (Lin's law) occurs (Lin 1972; Falkovich et al. 2001; LaCasce 2008). Thus, for an ideal 2D turbulence with a single energy input scale $\lambda$, Lin's law is expected to be valid for scales below $\lambda$ whereas Richardson's law is related to large-scale circulation (Salazar and Collins 2009). Both these flow regimes have been observed using observed and simulated drifters in the open ocean (Ollitrault et al. 2005) and in the Baltic Sea for different scales (Döös and Engqvist 2007). 
The spreading rate of pairs of drifters in the uppermost layer of the Gulf of Finland was studied using surface drifters (called GPS/GSM drifters) following motions at a depth down to about $1.5 \mathrm{~m}$ (Soomere et al. 2011). The drifters were therefore constrained to 2D flow. However, they may be influenced by the 3D turbulence of the ocean. Unlike for the SVP drifters, the inertial oscillations were not filtered out. As the filter did little change to the relative dispersion for the SVP drifters, it should not markedly influence the results from the GPS/GSM drifters either. Differently from a number of similar studies (Ollitrault et al. 2005; Döös and Engqvist 2007; Lumpkin and Elipot 2010) the experiments performed in the western and central part of the Gulf of Finland in August-October 2010 were concentrated on relatively small initial separations of the drifters $(\sim 100 \mathrm{~m})$. The deployments resulted in 7 pairs of drifter trajectories. As the signal from the drifters was lost at times, it was not possible to adequately calculate the detailed statistics of the drift but the recorded data still allowed quantification of the temporal evolution of the pair separations.

The observed trajectories reflected a variety of phenomena characteristic of the currents in the Gulf of Finland (Fig. 8.15): relatively small mesoscale eddies with a diameter of about $5 \mathrm{~km}$ to the north of Naissaar, inertial oscillations in the open part of the gulf, and relatively rapid and almost straight drift sections (cf. Kõuts et al. 2010; Verjovkina et al. 2010). While most of the trajectories were relatively short (shorter than $50 \mathrm{~km}$ ), one drifter covered more than $150 \mathrm{~km}$ during about two weeks and left the Gulf of Finland to the Gotland Sea.

Contrary to the previously mentioned theoretical expectation, Richardson's law has been found to describe spreading properties for small distances fairly well while Lin's law has proven a better fit for larger distances (Döös and Engqvist 2007). A probable reason for this counter-intuitive observation is that the character of spreading is particularly complicated for 2D flows occurring on the surface of 3D flows, which is often the case in strongly stratified environments. Velocity fields in such flows may be highly compressible ${ }^{5}$ and may exhibit a considerable decrease in the exponent $b$ in Eq. (8.12) compared to the pure 2D case (Bec et al. 2004; Kalda 2007). For a review of relevant laboratory experiments see Cressman et al. (2004). For realistic geophysical flows one might expect quite a large variation in the range of $1.5 \leq b<\infty$ of this exponent. Note that the Gulf of Finland is rather narrow and the separation process of drifters eventually becomes affected by the boundaries. The gulf is $\mathcal{O}\left(10^{5}\right) \mathrm{m}$ wide, but the drifters were not deployed in the middle of the it. There may therefore be some influence of the southern coast on the drift, e.g., the drifters could not move as far south as in the other directions.

The typical spreading rate was almost constant for all the pairs within the first 10-15 hours, or until the drifters were separated by about $150 \mathrm{~m}$, and increased considerably afterwards (Fig. 8.16). Although the estimates for initial distances below

\footnotetext{
${ }^{5}$ The (flow) compressibility (equivalently, the compressibility of the associated velocity field) is defined as the relative weight of the potential component in the decomposition of the net velocity field into solenoidal and potential components. See a more detailed discussion of this quantity in the context of the Baltic Sea in Giudici et al. (2012), Kalda et al. (2013).
} 

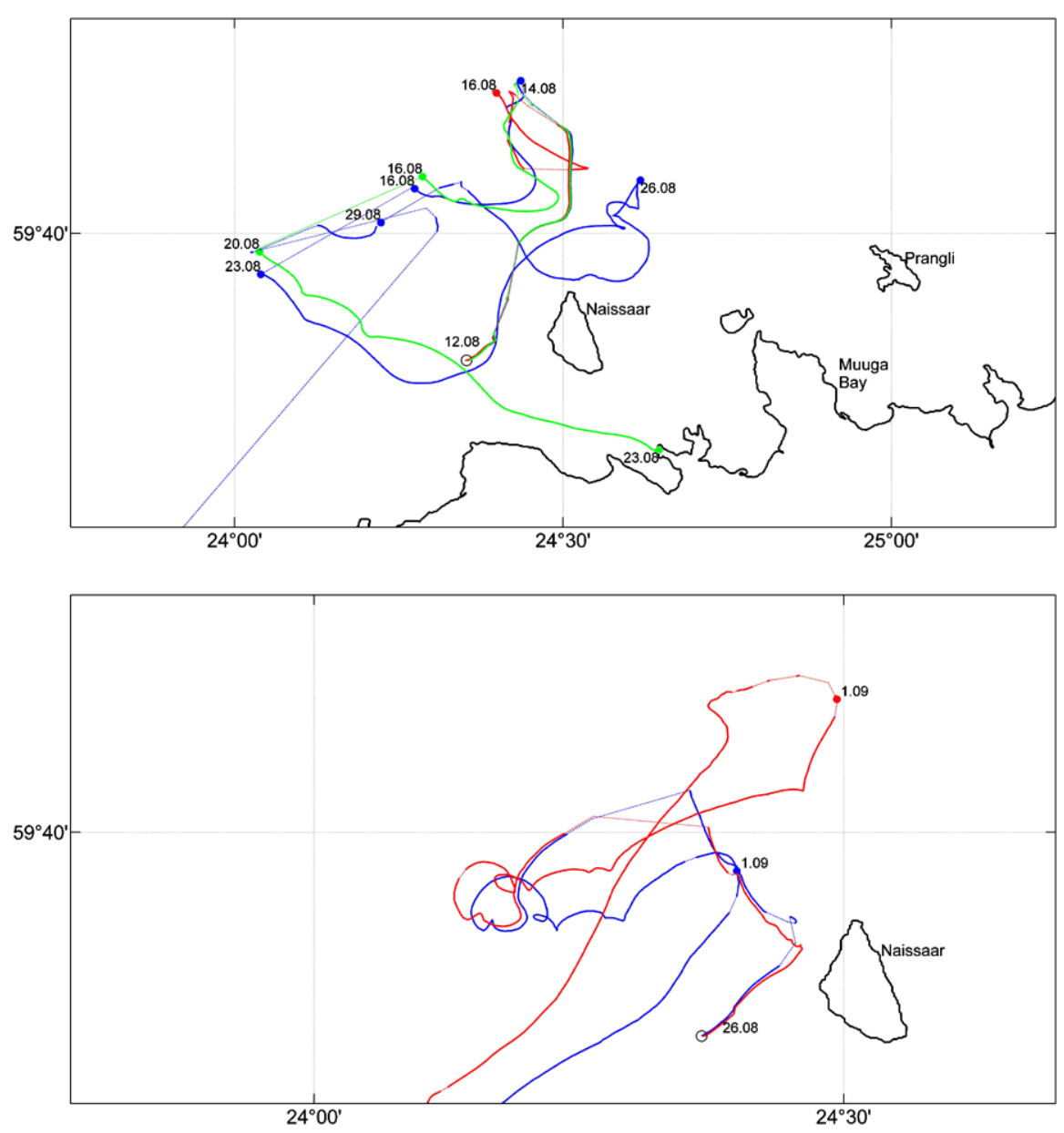

Fig. 8.15 Trajectories of drifters deployed on 12.08.2010 (upper panel) and on 26.08.2010 (bottom panel) in the Gulf of Finland. The deployment site is indicated by an empty circle. Thin straight sections of the trajectories represent intervals when the GSM signal was not available (Soomere et al. 2011)

$100 \mathrm{~m}$ should be interpreted as indicative because of possible uncertainties of GPSmeasured locations, such a behaviour suggests the presence of different regimes of spreading (either ballistic or Richardson's law) for drifter pairs up to separations of about $150 \mathrm{~m}$.

For drifters initially separated by less than $1 \mathrm{~km}$ the separation rate varied from about $100 \mathrm{~m} /$ day to $700 \mathrm{~m} /$ day. For even larger distances between the drifters (>600 m) it revealed somewhat different behaviour for different pairs. The distance persistently increased for several pairs but revealed quasi-regular oscillations for some other pairs. This phenomenon is common for the Gulf of Finland (cf. Ver- 


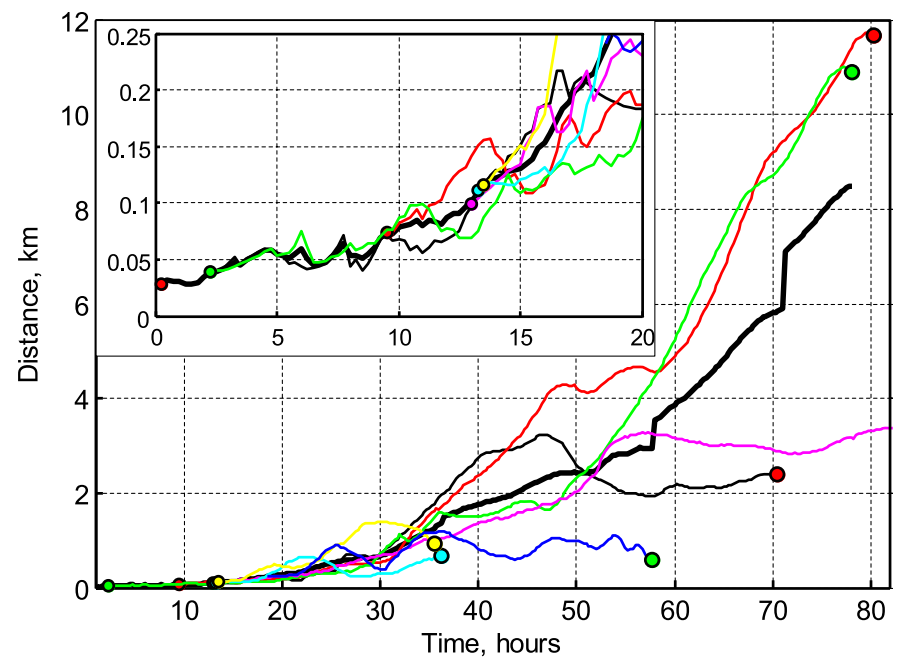

Fig. 8.16 Time series of the distance between pairs (colour lines) and the average distance (black thick line) in linear coordinates. Circles show the beginning and end of sensible measurements of the pairs' locations. The beginning time is chosen so that the initial separation of each pair matches the average distance of pairs deployed with initially smaller separation. The insert shows the pairs separation during the first 20 hours (Soomere et al. 2011)

jovkina et al. 2010) and apparently caused by relatively small mesoscale eddies with a diameter as small as about $400 \mathrm{~m}$.

The spreading rate owing to the impact of random walks on small scales (on the order of $\mathcal{O}(100) \mathrm{m}$ ) (Lumpkin and Elipot 2010) can be estimated from the initial sections of the trajectories of the pairs (i.e., from the parts that revealed no extensive quasi-periodic variations in the distance due to coherent mesoscale structures) of the drifter motion in Fig. 8.16. This rate is about 200-300 m/day, that is, about twice as large as hypothesized in Andrejev et al. (2010). This should not be confused with the random walk of drifters that are further apart ( $d$ much larger than the baroclinic Rossby radius), which also experience random walk when the motion of initially paired drifters has become uncorrelated.

\subsection{Power Law Representation of the Spreading Rate}

Data from the drifters in the uppermost layer suggest that the structure of small-scale turbulence in the study area may contain motions of substantially different character at different scales. The substantial decrease in the average spreading rate for distances of 1.6-3.2 km during a certain time interval (Fig. 8.16) is apparently due to a substantial impact from mesoscale eddies with a diameter matching the local baroclinic Rossby radius that, ideally, should be resolved by a regional circulation model. 


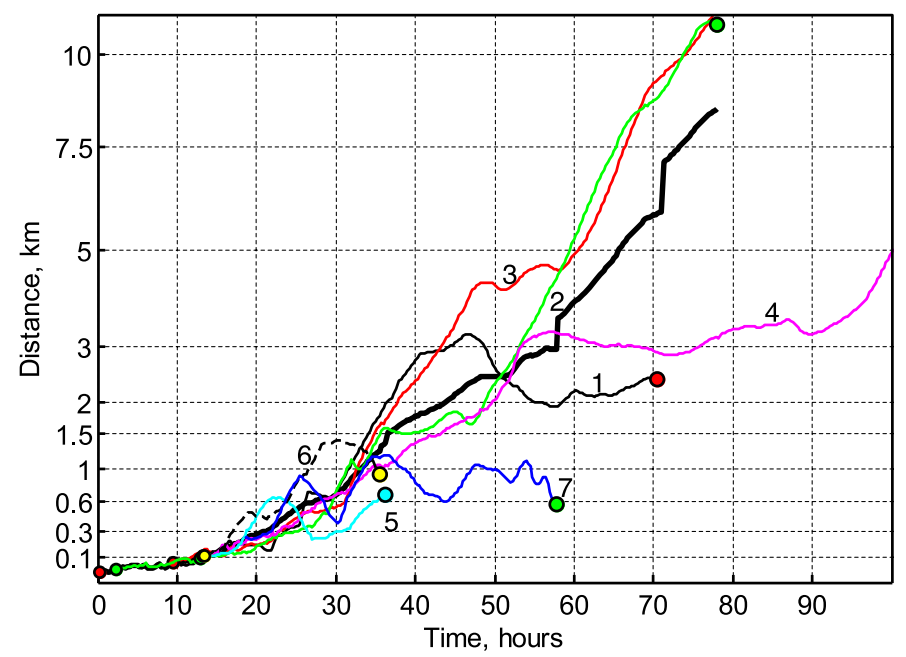

Fig. 8.17 Time series of the distance between pairs of drifters (colour lines) and of the average distance of pairs (black thick line) in linear-power law 2/3 coordinates Soomere et al. (2011)

It is interesting to analyse whether the dynamics of the study site is mostly governed by the 3D (local) turbulence or by a 2D (large-scale) motion system. The distance between paired drifters increased approximately linearly in the linear-power law $2 / 3$ coordinates (corresponding to the theoretical spreading rate for the $3 \mathrm{D}$ turbulence) up to values of about $400 \mathrm{~m}$ or about 25 hours, after which the separation rate increased for most pairs. Remarkably, two pairs ( $2 \& 3$ in Fig. 8.17) revealed a linear increase in their distance in this framework after 2-2.5 days, which suggests that they were involved into mostly $3 \mathrm{D}$ turbulent motions. Again, these drifters were not filtered like the SVP. At the end of this part of motion, the distance between the drifters was more than $4 \mathrm{~km}$, a scale which is usually resolved by contemporary regional circulation models of the Baltic Sea. The drifters in question were deployed on 12 August 2010 in relatively calm weather conditions and thus were only weakly, if at all, impacted by the wind.

The above findings suggest that there probably exists no single proper fit of the exponent $b$ in the power law $d \sim t^{b}$ in Eq. (8.12). This assumption is confirmed by the analysis in $\log -\log$ coordinates (Fig. 8.18). For relatively small separations $(<70 \mathrm{~m}$ in the initial phase of the drift, up to 8 hours) the exponent $b$ was in the range $0.23-0.3$, with a mean value of 0.27 . Therefore, the separation rate is governed by a ballistic law rather than Richardson's law in this situation. As none of these laws dominated, certain specific mechanisms, such as shear dispersion (particle separation due to spatial variations in the velocity field) or specific surface-layer dispersion (induced by the gradient of the energy dissipation rate in the turbulent surface layer, Skvortsov et al. 2010) may govern the initial particle separation rate. Modelling of separations on small scales (Orre et al. 2006) has revealed spreading rates slightly lower than expected, possibly due to the lateral boundaries affecting the drifters. It is possible that this, to some extent, also is the case in this study. 


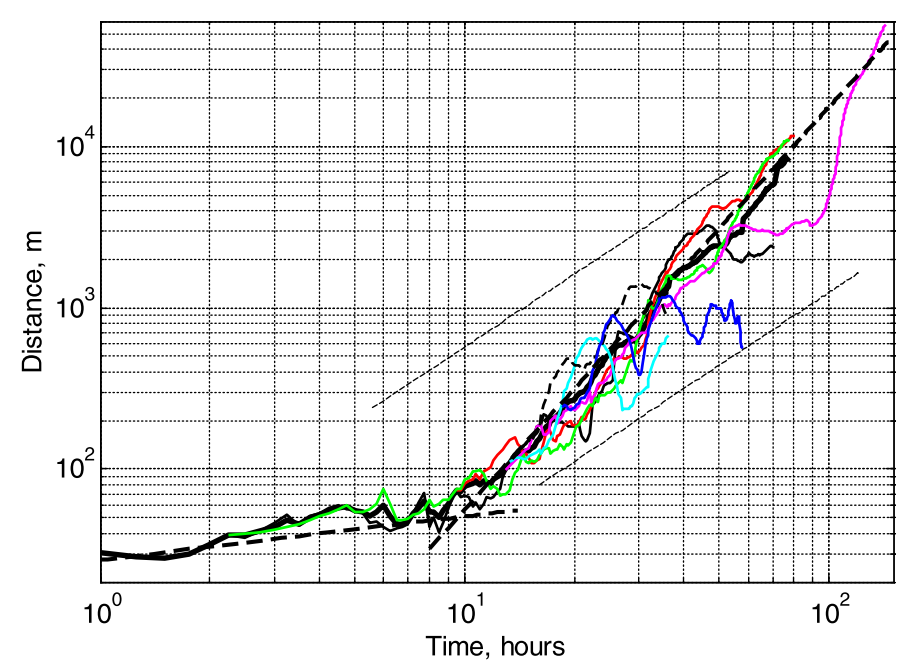

Fig. 8.18 Time series of the distance between pairs of drifters (colour lines) and of the average distance (black thick line) in log-log coordinates. Bold dashed lines correspond to the power laws with $b=0.27$ (time interval 1-10.5 hours) and $b=2.5$ (time interval 8-105 hours). Thin dashed lines correspond to Richardson's law with $b=1.5$ (Soomere et al. 2011)

Starting from a separation of about $100 \mathrm{~m}$ (or a drift time of 10 hours), the separation rates were different. Two pairs in Fig. 8.18 displayed coherent motions and thus separated poorly, reflected by $b=1.3$ and $b=0.88$ being the best fits for these pairs. All other pairs revealed a surprising agreement in spreading rates. The exponent $b$ for them varied from 2.12 to 2.72 , with the average value of $b \approx 2.5$. Including or excluding the two pairs mentioned before did not change this average significantly. The resulting value is of a reasonable magnitude compared to the infinite exponent characterizing 2D flows, yet clearly larger than the classical value of $b=1.5$ that corresponds to Richardson's law and is characteristic to the 3D turbulent motions. Therefore, in the study area the dynamics was predominantly governed by 3D flows but the contribution of a 2D motion system was still substantial.

\subsection{Discussion and Conclusions}

Results from deployments of surface and subsurface drifters in the Baltic Sea during the summers of 2010 and 2011 have been presented. Two types of drifters were used. The SVP (sub)surface drifters have a $18 \mathrm{~m}$ drogue depth and represent motions of water masses between 12-18 m depth (Fig. 8.1a). The other (GPS/GSM) drifters were designed to represent only the currents in the uppermost $1.5 \mathrm{~m}$ thick layer (Fig. 8.15).

The average lifetime of a SVP drifter was 80 days (Table 8.1). These drifters were used to map some geographical aspects of subsurface currents in the Baltic Proper 
(Fig. 8.3a), and to obtain values of mean displacement and absolute and relative dispersion (Figs. 8.6 and 8.11). Statistical parameters of drift characterizing a substantial part of the Baltic Proper were derived from the SVP drifter data by means of splitting the time series into basically uncorrelated segments of $\sim 11$ days each. The resulting statistics was compared to a similar one extracted from the motion of drifters simulated by a trajectory model starting at the same position and time as the SVP drifter segments (Fig. 8.1b).

In order to remove inertial oscillations, which were well observed in the drifter data but not very well in the model results, all drifter segments and the simulated drifters were filtered using a 14-hour running mean. As the ocean model data were not available for 2010 and 2011, the drifter segments had to be compared to simulated drifters in the years available, 1962-2004. As such, the motion of a drifter segment could not be directly compared to any specific simulated drifter. However, some indications followed from a statistical comparison.

The mean displacement and absolute dispersion were found to be significantly lower for the simulated than for the observed drifters (Fig. 8.6). This property was attributed to the model velocities being lower and less variable, as shown by comparing the probability distributions of Lagrangian velocities from drifters to that of the model trajectories (Fig. 8.7).

Near-surface currents are, to some extent, wind-driven on time scales comparable to the duration of the drifter segments (Leppäranta and Myrberg 2009). The quality of simulated near-surface currents thus partly depends on the quality of the wind forcing, mixed-layer depth, and parameterization. Meier (2002) compared temperature and salinity profiles modelled using the RCO model to observations and found good agreement in mixed-layer depth. The wind forcing (ERA-40 winds, dynamically downscaled by the RCA model) was corrected using a parameterization of wind gusts by Höglund et al. (2009) as the wind speeds were found not to be variable enough. The correction yielded somewhat more realistic frequency distributions of the wind speeds. However, this does not imply that the wind at a specific point or time became more realistic. In particular, the root-mean-square errors may very well have increased with this correction. Furthermore, the study of Höglund et al. (2009) was limited to the Swedish coastal regions, as no observations over open water were available. Thus, there is no information about the quality of the wind forcing over open water, although it is likely to share some of the problems of the coastal winds. It is thus conceivable that errors in the subsurface currents, to a large part, are due to errors in the wind field from the RCA model output.

In principle, the discrepancy may reflect the possibility that the years 2010-2011 could have been 'extreme' in terms of absolute dispersion. However, Fig. 8.6, suggests that such 'extreme' years are quite uncommon, and the likelihood that they would occur over a two-year period is thus even smaller. The number of SVP drifters is also relatively small, and the data may be somewhat biased as two of the drifter pairs stayed together for nearly 20 days, and thus both drifters in the pairs sampled the same dynamical region. However, this only affects a few segments out of the total 76 used.

SVP drifters are seldom fully submerged into the water and may thus be affected by the winds. Langmuir currents, Stokes drift, and waves may also effect the drifters 
in a manner not represented in the RCO model. However, due to the drogue anchored at 12 to $18 \mathrm{~m}$ depth, the SVP drifters in the World Ocean have been shown to follow the currents at the drogue depth with only small deviations (Niiler et al. 1995). A difference between the open ocean and the Baltic Sea is that the latter has a much shallower thermocline, which in some cases is situated at the drogue depth. This could result in a shear on the drogue, in which case the effect on the drifter is uncertain. For this reason, it would be interesting to equip future drifters with a temperature sensor at both the top and bottom of the drogue to identify these events.

Multiplying the velocities of the RCO model output by a factor 1.25 or including parameterized subgrid turbulence resulted in a clearly better agreement between several statistical characteristics of observed and simulated drifters such as distribution of velocities, absolute dispersion and mean displacement. Although both methods yielded similar results for mean displacement, the results were very different in terms of some other metrics. The Lagrangian integral time scale was severely shortened after adding subgrid turbulence. The resulting time scales were shorter than those of the recorded drifter segments.

The random motions introduced through the turbulence parameterization (Döös et al. 2011) do not take the original velocity into account, thus changing both the velocity and properties of the trajectory somewhat. The transport speed can thus be improved with this parameterization, but at the cost of changes in, e.g., the transport direction. If one needs to tune the motion of simulated drifters for single-particle statistics, multiplying the simulated velocities by a constant factor would then be a reasonable choice: it increases the speed but does not alter the properties of the trajectory. This choice is however poor if the relative dispersion needs to be adjusted since small, subgrid scale changes in the direction are needed to separate initially closely located simulated drifters.

Furthermore, even when the simulated drifters were separated by at least one grid box, the further separation rates were lower than the average rate for the SVP drifters. Therefore, subgrid parameterization is needed also on larger scales $\left(D_{R}^{2}>4 \mathrm{~km}\right)$. In this study, simulated drifters were tuned to resemble the mean displacement and absolute dispersion of observed SVP drifters. It would be possible to instead tune them to yield good fit to observed relative dispersion, depending on whether transport or spreading is the most crucial metric for the study. It is possible that using a higher-order turbulence scheme such as 'Markov 1' or 'Markov 2' (Rupolo 2007), thereby taking, e.g., velocity autocorrelation into account, would give better results by combining the benefits of both methods used in this study. The higher-order Markov models have been found to better describe the motions of water particles than the 'Markov 0' model (Griffa 1996). Such schemes may be implemented in TRACMASS in the future.

The comparison between simulated drifters and observed SVP-B drifters indicates that the RCO model simulates correctly neither the mean flow nor the turbulent flow. Using values roughly estimated from Figs. 8.6 and 8.10, some implications for Lagrangian modelling without tuning can be identified. If the simulated drifters have $4 / 5$ of the mean displacement of the SVP drifter segments, this would mean that if simulated particles, on average, travel $100 \mathrm{~km}$ in 10 days, a drifter, or a real 
water particle, would, on average travel $\sim 125 \mathrm{~km}$ in those 10 days. By the same argument, if simulated particles are estimated to reach the coast in 10 days, real water particles would make the same journey in $<8$ days. Furthermore, water particles contained within a $<1 \mathrm{~km}$ radius initially would spread over an area of $12 \mathrm{~km}$ radius in 25 days, while their model counterparts would disperse to cover $<10 \mathrm{~km}$ radius. Such conclusions would have impacts when estimating the fate of oil spills or other pollutants. However, we wish to stress that we have compared observations from 2010-2011 with model data from 1962-2004, and that the drifter data is limited.

To make the comparison of modelled and observed properties fair, and to yield more confidence in the magnitudes of the tuning needed would require model data for the years 2010-2011. This could, however, take a few years as the RCO model is being decommissioned in favour of a new regional ocean model, based on the Nucleus of European Modelling (NEMO) ocean circulation model (Madec 2009). The wind forcing will most likely also need updating, as the ERA-40 data set is to be replaced by ERA-Interim and eventually by ERA-75, while the RCA model used for downscaling is also likely to be decommissioned. If SVP-B drifter data is continued to be gathered for the Baltic Sea, this data could be used to validate and perhaps tune the next generation of Baltic Sea models.

The presented results from the drifters in the uppermost layer of the Gulf of Finland indicate substantial differences in the dynamics of the vertically integrated relatively thick subsurface layer and the uppermost layer with a thickness of 1$1.5 \mathrm{~m}$ (which is where, e.g., oil spills or smaller lost items are transported). Although the average spreading rate generally increased with time or the distance between drifters, the well-known Richardson's law did not satisfactorily explain the transport in the uppermost layer of the Gulf of Finland. For the separation $d$ of drifter pairs on short time scales (less than 8 hours) or separation distances (from the first tens of meters up to about 100-150 m), a power law $d \sim t^{0.27}$ described the spreading much better. Starting from this threshold, the distance then increased, in average, according to a power law $d \sim t^{2.5}$. The spreading rate was about $200 \mathrm{~m} /$ day for separations below $0.5 \mathrm{~km}, 500 \mathrm{~m}$ /day for separations below $1 \mathrm{~km}$ and in the range of $0.5-3 \mathrm{~km} /$ day for separations in the range of $1-4 \mathrm{~km}$.

As a considerable part of the drifters following the uppermost $1.5 \mathrm{~m}$ thick layer was above the water surface, their drift was impacted by wind properties to some extent. For example, a wind speed of $5 \mathrm{~m} / \mathrm{s}$ may, technically, yield a contribution of about $10 \mathrm{~cm} / \mathrm{s}$ to the drift speed (Soomere et al. 2011). Although this value is on the order of the current speed, it does not significantly effect the separation of drifters, as the wind patterns over sea surface are much more homogeneous compared to similar winds over the mainland. Therefore, it is natural to expect that the impact of wind on closely located drifters mostly resulted in their concurrent downwind drift. This would imply that winds can influence absolute dispersion while their impact on relative dispersion would be negligible.

The results from the drifters in the uppermost layer suggest that a realistic parameterization of subgrid-scale processes in the Gulf of Finland strongly depends on the resolution of the ocean model. It is well known that models with spatial resolution coarser than $2 \mathrm{~km}$ cannot resolve mesoscale dynamics in this region (see Chap. 6 
for more details). Their parameterization of subgrid processes should correspond to a typical spreading rate of about $2 \mathrm{~km} /$ day. The same rate is reasonable for models with a resolution of about $1-2 \mathrm{~km}$ while the models with a resolution of $\sim 1 \mathrm{~km}$ might use the rate of about $700 \mathrm{~m} /$ day. Parameterizations leading to spreading rates of 300-500 m/day may be recommended for extremely high-resolution models with a grid step of $\sim 0.5 \mathrm{~km}$. As the drifters in the uppermost layer have experienced a certain impact of the local wind and waves on their drift the presented rates may to some extent overestimate the actual spreading rates but the order of magnitude for the spreading effects extracted from the experiments evidently is realistic.

The parameters characterizing the dynamics of spreading of objects in the uppermost layer are of utmost importance for the technique developed in this book. Its key idea is to use the Lagrangian dynamics of currents to develop methods for the reduction of environmental risks. Its key component is statistical analysis of large sets of Lagrangian trajectories of simulated drifters or water particles. The results are evidently highly sensitive with respect to the parameterization of subgrid-scale processes that may randomly redirect drifters to largely different sea areas compared to the modelled fields of currents (Döös 1995; de Vries and Döös 2001; Griffa et al. 2004; Andrejev et al. 2010).

The problem is even more complicated in strongly stratified sea areas such as the Gulf of Finland where the drift is frequently steered by multi-layered dynamics (Andrejev et al. 2004; Gästgifvars et al. 2006) and where it is not clear beforehand which theoretical framework (predomination of 2D or 3D motion systems) should be used in the analysis.

Similar problems intrinsically arise in the attempts of modelling pathways of different water masses (Meier 2007) and especially in simulations, both in forecast and hindcast modes, of pollution transport by regional ocean models such as HIROMB or Seatrack Web (Funkquist 2001; Gästgifvars et al. 2006; Verjovkina et al. 2010). This chapter has contributed by presenting results from recently deployed surface drifters of different types as well as drifters simulated with an ocean model and a trajectory code, and comparing these to each other and the theoretical expectations and discussing the implications for Lagrangian modelling in the Baltic Sea.

Acknowledgements This study was performed in the framework of the BalticWay project, which was jointly supported by the funding from the by the Swedish Research Council for Environment, Agricultural Sciences and Spatial Planning (Formas, Ref. No. 2008-1900), Estonian Science Foundation and the European Commission's Seventh Framework Programme (FP7 20072013) under grant agreement No. 217246 made with the joint Baltic Sea research and development programme BONUS. The research was partially supported by the Estonian Science Foundation (grant No. 9125), targeted financing by the Estonian Ministry of Education and Research (grant SF0140007s11), and by the European Regional Development Fund via support to the Centre of Excellence for Non-linear Studies CENS. The authors wish to thank Tallink Silja shipping company for allowing us to deploy the SVP drifters from the Stockholm-Riga line and in particular we wish to thank Captain Lembit Uustulnd and his crew on M/S Silja Festival for permission and help in deployment of the drifters. We also acknowledge and appreciate the help given by Prof. Peter Lundberg and Dr. Anders Engqvist in deployment. The experiments with the surface drifters in the Gulf of Finland were performed very professionally by Mr Mikk Viidebaum. His cooperation towards deployment and rescue of SVP drifters is also gratefully acknowledged. Finally, we also express our gratitude to Markus Meier and Anders Höglund at the Swedish Meteorological and 
Hydrological Institute for providing the RCO data as well as help and fruitful discussions about it. All trajectory simulations have been made using supercomputers maintained by NSC at Linköping University, Sweden.

\section{References}

Andrejev O, Myrberg K, Alenius P, Lundberg PA (2004) Mean circulation and water exchange in the Gulf of Finland - a study based on three-dimensional modelling. Boreal Environ Res 9:1-16

Andrejev O, Sokolov A, Soomere T, Värv R, Viikmäe B (2010) The use of high-resolution bathymetry for circulation modelling in the Gulf of Finland. Est J Eng 16:187-210

Bec J, Gawedzki K, Horvai P (2004) Multifractal clustering in compressible flows. Phys Rev Lett 92:224501

Blanke B, Raynaud S (1997) Kinematics of the Pacific Equatorial Undercurrent: an Eulerian and Lagangian approach from GCM results. J Phys Oceanogr 27:1038-1053

Corell H, Moksnes PO, Engqvist A, Döös K, Jonsson P (2012) Larval depth distribution critically affects dispersal distance and optimum size for marine protected areas. Mar Ecol Prog Ser 467:29-46

Cressman J, Davoudi J, Goldburg W, Schumacher J (2004) Eulerian and Lagrangian studies in surface flow turbulence. New J Phys 6:53

de Vries P, Döös K (2001) Calculating Lagrangian trajectories using time-dependent velocity fields. J Atmos Ocean Technol 18:1092-1101

Döös K (1995) Inter-ocean exchange of water masses. J Geophys Res-Oceans 100:13,499_ 13,514

Döös K, Meier HEM, Döscher R (2004) The Baltic haline conveyor belt or the overturning circulation and mixing in the Baltic. Ambio 33:261-266

Döös K, Rupolo V, Brodeau L (2011) Dispersion of surface drifters and model-simulated trajectories. Ocean Model 39:301-310

Döös K, Engqvist A (2007) Assessment of water exchange between a discharge region and the open sea-a comparison of different methodological concepts. Estuar Coast Shelf Sci 74:585597

Döscher R, Willén U, Jones C, Rutgersson A, Meier HEM, Hansson U, Graham LP (2002) The development of the regional coupled ocean-atmosphere model RCAO. Boreal Environ Res 7:183192

Falkovich G, Gawedzki K, Vergassola M (2001) Particles and fields in fluid turbulence. Rev Mod Phys 73:913-975

Funkquist F (2001) HIROMB, an operational eddy-resolving model for the Baltic Sea. Bull Mar Inst Gdańsk 28:7-16

Garfield N, Maltrud M, Collins C, Rago T, Paquette R (2001) Lagrangian flow in the California Undercurrent, an observation and model comparison. J Mar Syst 29:201-220

Garraffo ZD, Mariano AJ, Griffa A, Veneziani C, Chassignet EP (2001) Lagrangian data in a highresolution numerical simulation of the North Atlantic I. Comparison with in situ drifter data. J Mar Syst 29:157-176

Gästgifvars M, Lauri H, Sarkanen A-K, Myrberg K, Andrejev O, Ambjörn C (2006) Modelling surface drifting of buoys during a rapidly-moving weather front in the Gulf of Finland, Baltic Sea. Estuar Coast Shelf Sci 70:567-576

Giudici A, Kalda J, Soomere T (2012) On the compressibility of surface currents in the Gulf of Finland, the Baltic Sea. In: Proceedings of the IEEE/OES Baltic 2012 international symposium "Ocean: past, present and future. Climate change research, ocean observation \& advanced technologies for regional sustainability”, Klaipeda, Lithuania, May 8-11, 2012. IEEE Press, New York, $8 \mathrm{pp}$ 
Griffa A (1996) Applications of stochastic particle models to oceanographic problems. In: Adler RJ, Müller P, Rozovskii BL (eds) Stochastic modelling in physical oceanography. Birkhäuser Boston, Cambridge, pp 113-140

Griffa A, Piterbarg LI, Özgökmen T (2004) Predictability of Lagrangian particle trajectories: effects of smoothing of the underlying Eulerian flow. J Mar Res 62:1-35

Håkansson B, Rahm L (1993) Swedish Lagrangian current experiments. In: Gulf of Bothnia year 1991-physical transport experiments, vol 15, pp 41-55. SMHI, RO

Höglund A, Meier HEM, Broman B, Kriezi E (2009) Validation and correction of regionalised ERA-40 wind fields over the Baltic Sea using the Rossby Centre Atmosphere Model RCA3.0. Rapport Oceanografi No 97, Swedish Meteorological and Hydrological Institute, Norrköping, Sweden

Kalda J (2007) Sticky particles in compressible flows: aggregation and Richardson's law. Phys Rev Lett 98:064501

Kalda J, Soomere T, Giudici A (2013) On the finite-time compressibility of the surface currents in the Gulf of Finland, the Baltic Sea. J Mar Syst. doi:10.1016/j.jmarsys.2012.08.010

Keevallik S, Soomere T (2010) Towards quantifying variations in wind parameters across the Gulf of Finland. Est J Earth Sci 59:288-297

Kjellsson J, Döös K (2012) Surface drifters and model trajectories in the Baltic Sea. Boreal Environ Res 17:447-459

Kjellström E, Bärring L, Gollvik S, Hansson U, Jones C, Samuelsson P, Rummukainen M, Ullerstig A, Willén U, Wyser K (2005) A 140-year simulation of European climate with the new version of the Rossby Centre Regional Atmospheric Climate Model (RCA3). Reports meteorology and climatology, vol 108

Kõuts T, Verjovkina S, Lagemaa P, Raudsepp U (2010) Use of lightweight on-line GPS drifters for surface current and ice drift observations. In: 2010 IEEE/OES US/EU Baltic international symposium, Riga, Latvia, August 25-27, 2010. IEEE Press, New York, 10 pp

Launiainen J, Stipa T, Grönwall H, Vihma T (1993) Finnish Lagrangian current experiments. In: Gulf of Bothnia year 1991-physical transport experiments, vol 15, pp 55-67. SMHI, RO

LaCasce J (2008) Statistics from Lagrangian observations. Prog Oceanogr 77:1-29

Leppäranta M, Myrberg K (2009) Physical oceanography of the Baltic Sea. Springer, Berlin, $378 \mathrm{pp}$

Lin J (1972) Relative dispersion in the enstrophy-cascading inertial range of homogeneous twodimensional turbulence. J Atmos Sci 29:394-396

Lumpkin R, Elipot S (2010) Surface drifter pair spreading in the North Atlantic. J Geophys ResOceans 115:C12017

Lumpkin J, Pazos M (2007) Measuring surface currents with Surface Velocity Program drifters: the instrument, its data, and some recent results. In: Griffa A, Kirwan A, Mariano A, Özgökmen T, Rossby $\mathrm{T}$ (eds) Lagrangian analysis and prediction of coastal and ocean dynamics. Cambridge University Press, New York, pp 39-68

Lumpkin R, Treguier AM, Speer K (2002) Lagrangian eddy scales in the Northern Atlantic Ocean. J Phys Oceanogr 32:2425-2440

Madec G (2009) NEMO ocean engine. Note du Pole de modélisation. Institut Pierre-Simon Laplace (IPSL), France, No 27, ISSN No 1288-1619, 217 pp

McClean JL, Poulain PM, Pelton J, Maltrud ME (2002) Eulerian and Lagrangian statistics from surface drifters and a high-resolution POP simulation in the North Atlantic. J Phys Oceanogr 32:2472-2491

Meier HEM, Döscher R, Coward AC, Nycander J, Döös K (1999) RCO—Rossby Centre regional Ocean climate model: model description (version 1.0) and first results from the hindcast period 1992/93. SMHI reports oceanography, vol 26

Meier HEM (2002) Regional ocean climate simulations with a 3D ice-ocean model for the Baltic Sea. Part 1: Model experiments and results for temperature and salinity. Clim Dyn 19:237-253

Meier HEM (2007) Modeling the pathways and ages of inflowing salt- and freshwater in the Baltic Sea. Estuar Coast Shelf Sci 74:610-627 
Meier HEM, Döscher R, Faxén T (2003) A multiprocessor coupled ice-ocean model for the Baltic Sea: application to salt inflow. J Geophys Res-Oceans 108:C3273

Myrberg K, Ryabchenko V, Isaev A, Vankevich R, Andrejev O, Bendtsen J, Erichsen A, Funkquist L, Inkala A, Neelov I, Rasmus K, Rodriguez Medina M, Raudsepp U, Passenko J, Söderkvist J, Sokolov A, Kuosa H, Anderson TR, Lehmann A, Skogen MD (2010) Validation of three-dimensional hydrodynamic models in the Gulf of Finland based on a statistical analysis of a six-model ensemble. Boreal Environ Res 15:453-479

Niiler PP, Sybrandy AS, Kenong B, Poulain PM, Bitterman D (1995) Measurements of the waterfollowing capability of holey-sock and tristar drifters. Deep-Sea Res 42:1951-1964

Ollitrault M, Gabillet C, Colin de Verdiere A (2005) Open ocean regimes of relative dispersion. J Fluid Mech 533:381-407

Orre S, Gjevik B, LaCasce JH (2006) Characterizing chaotic dispersion in a coastal tidal model. Cont Shelf Res 26:1360-1374

Pizzigalli C, Rupolo V, Lombardi E, Blanke B (2007) Seasonal probability dispersion maps in the Mediterranean Sea obtained from the Mediterranean forecasting system Eulerian velocity fields. J Geophys Res-Oceans 112:C05012

Poje AC, Haza AC, Özgökmen TM, Magaldi MG, Garraffo ZD (2010) Resolution dependent relative dispersion statistics in a hierarchy of ocean models. Ocean Model 31:36-50

Richardson LF (1926) Atmospheric diffusion shown on a distance-neighbour graph. Proc R Soc A 110:709-737

Rupolo V (2007) Observing turbulence regimes and Lagrangian dispersal properties in the ocean. In: Griffa A, Kirwan A, Mariano A, Özgökmen T, Rossby T (eds) Lagrangian analysis and prediction of coastal and ocean dynamics. Cambridge University Press, New York, pp 231-275

Salazar JPLC, Collins LR (2009) Two-particle dispersion in isotropic turbulent flows. Annu Rev Fluid Mech 41:405-432

Skvortsov A, Jamriska M, DuBois TC (2010) Scaling laws of passive tracer dispersion in the turbulent surface layer. Phys Rev E 82:056304

Soomere T, Viikmäe B, Delpeche N, Myrberg K (2010) Towards identification of areas of reduced risk in the Gulf of Finland, the Baltic Sea. Proc Est Acad Sci 59:156-165

Soomere T, Viidebaum M, Kalda J (2011) On dispersion properties of surface motions in the Gulf of Finland. Proc Est Acad Sci 60:269-279

Uppala SM, Kållberg PW, Simmons AJ, Andrae U, da Costa Bechtold V, Fiorino M, Gibson JK, Haseler J, Hernandez A, Kelly GA, Li X, Onogi K, Saarinen S, Sokka N, Allan RP, Andersson E, Arpe K, Balmaseda MA, Beljaars ACM, van de Berg L, Bidlot J, Bormann N, Caires S, Chevallier F, Dethof A, Dragosavac M, Fisher M, Fuentes M, Hagemann S, Hólm E, Hoskins BJ, Isaksen L, Janssen PAEM, Jenne R, McNally AP, Mahfouf J-F, Morcrette J-J, Rayner NA, Saunders RW, Simon P, Sterl A, Trenberth KE, Untch A, Vasiljevic D, Viterbo P, Woollen J (2005) The ERA-40 re-analysis. Q J R Meteorol Soc 131:2961-3012

Verjovkina S, Raudsepp U, Kõuts T, Vahter K (2010) Validation of Seatrack Web using surface drifters in the Gulf of Finland and Baltic Proper. In: 2010 IEEE/OES US/EU Baltic international symposium, Riga, Latvia, August 25-27, 2010. IEEE Press, New York, 7 pp

Webb DJ, Coward AC, de Cuevas BA, Gwilliam GS (1997) A multiprocessor ocean circulation model using message passing. J Atmos Ocean Technol 14:175-183 